\title{
WestVirginiaUniversity
}

THE RESEARCH REPOSITORY @ WVU

Graduate Theses, Dissertations, and Problem Reports

2021

\section{Selected Principles of Practicing for Security in Performance}

\author{
Hsing-Yi Tsai \\ West Virginia University, ht0020@mix.wvu.edu
}

Follow this and additional works at: https://researchrepository.wvu.edu/etd

Part of the Music Performance Commons, and the Music Practice Commons

\section{Recommended Citation}

Tsai, Hsing-Yi, "Selected Principles of Practicing for Security in Performance" (2021). Graduate Theses, Dissertations, and Problem Reports. 8057.

https://researchrepository.wvu.edu/etd/8057

This Dissertation is protected by copyright and/or related rights. It has been brought to you by the The Research Repository @ WVU with permission from the rights-holder(s). You are free to use this Dissertation in any way that is permitted by the copyright and related rights legislation that applies to your use. For other uses you must obtain permission from the rights-holder(s) directly, unless additional rights are indicated by a Creative Commons license in the record and/ or on the work itself. This Dissertation has been accepted for inclusion in WVU Graduate Theses, Dissertations, and Problem Reports collection by an authorized administrator of The Research Repository @ WVU.

For more information, please contact researchrepository@mail.wvu.edu. 
Selected Principles of Practicing for Security in Performance

Hsing-Yi Tsai

Research project submitted to the College of Creative Arts at West Virginia University

In partial fulfillment of the requirements for the degree of

Doctor of Musical Arts

in Piano Performance

Peter Amstutz, DMA, Chair

Lucy Mauro, DMA

Matthew Heap, PhD

Bruce Kang, PhD

School of Music

Morgantown, West Virginia

2021

Keywords: Memorization, Piano Performance

Copyright (C2021 by Hsing-Yi Tsai

All rights reserved 


\begin{abstract}
Selected Principles of Practicing for Security in Performance
\end{abstract}

\title{
Hsing-Yi Tsai
}

This research focuses on extending the imagination for the purposes of activating our brain to strengthen memorization of music for a stronger and more secure performance. This research explores the concept of self-awareness in the sense of having a conversation with ourselves in order to understand the primary reasons we pianists spend hours in the practice room. I introduce selected strategies for learning pieces through a meticulous process of memorization which impacts not only new pieces, but also the resurrecting of old repertoire. Along with including the concept of the Memory Palace, I explore different methods of memorizing music to relieve pianists' unnecessary anxiety about performing from memory. Lastly, the final chapter examines the relationship between the performance and the influence of the teacher, based on my own personal experiences. 


\section{Acknowledgments}

I would like to express my appreciation to all who have supported me and shared love with me during my music journey. I am also deeply thankful to all the people who disappointed me and did not value me-without you I could not have gone this far and become so strong.

Firstly, I would like to express my deep gratitude to my family for their invaluable support and love, who with no hesitation completely supported my decision to follow my desire of attending music school instead of medical school. With total support they saw me eagerly jump into the airplane and leave for study on the other side of the earth, 7864 miles away from home. Thank you for encouraging me to pursue my dream.

I would like to extend my deepest gratitude to Dr. Peter Amstutz, my professor, mentor, and friend-you are truly family to me. I would not be where I am today without people like you by my side. Thank you for being a supportive and loving person. Your constant encouragement has been invaluable. This world needs more people like you, who sincerely care about others and share supportive love to the entire world. As the old proverb about teacher and student would have it, thank you for inviting me to stand on your shoulders so that I can see further than ever before.

A special thanks to John Rose, for supporting me, proof-reading my paper, and making me feel blessed every day. Also my deep gratitude to Mr. Randy Ames and his family (my American host family) and to Dr. Wesley Roberts for supporting me since my first landing in the USA. Finally, sincerest appreciation to all members of my committee: Dr. Lucy Mauro, Dr. Matthew Heap, and Dr. Bruce Kang. Thank you for your suggestions and guidance. 
Table of Contents

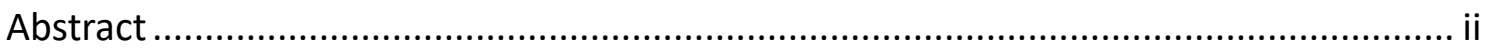

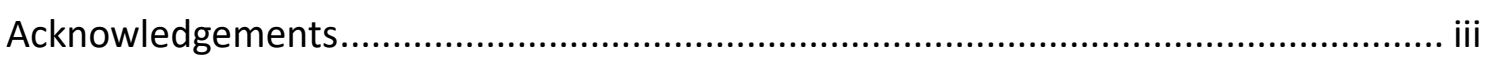

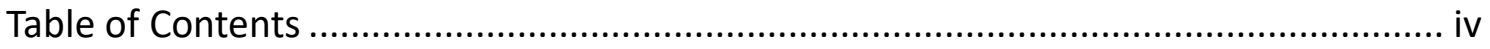

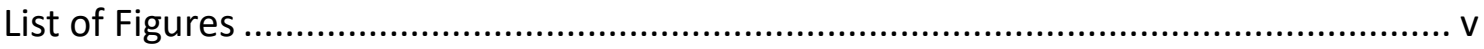

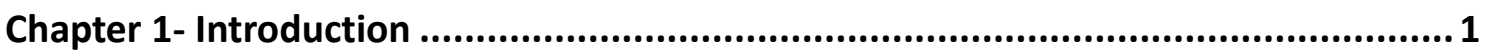

1-1 Having a Conversation with Yourself ...................................................... 3

1-2 Do you feel good about playing music? Or does playing music make you feel

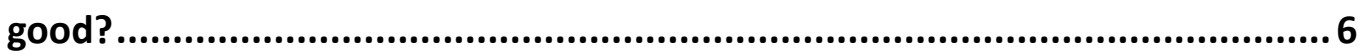

Soaking in a self-sweetness jar ........................................................... 7

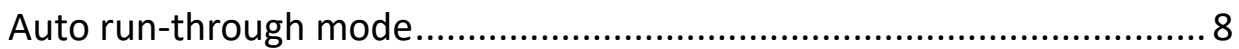

I can play faster than you, you, and you .............................................. 12

Hey, playing faster does help! ........................................................... 15

Mistakes are our friends ................................................................... 21

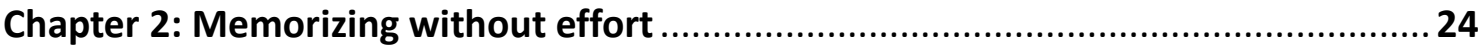

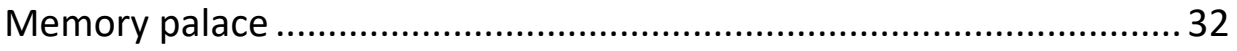

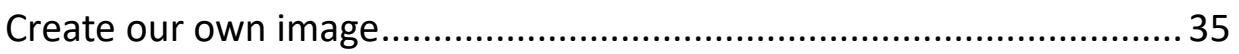

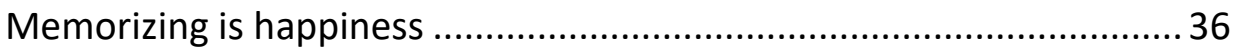

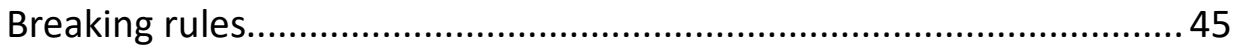

The shape of hand movement and directionality on keyboard.............. 46

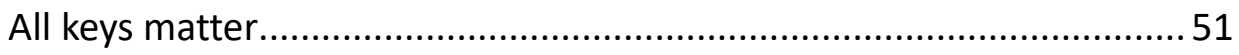

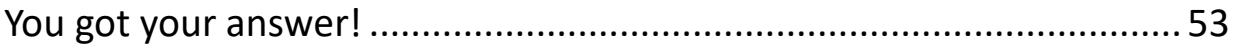

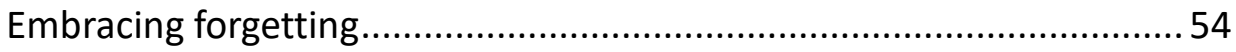

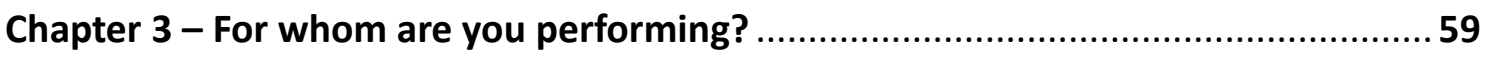

Conclusion: The two most powerful things in the world...........................................63

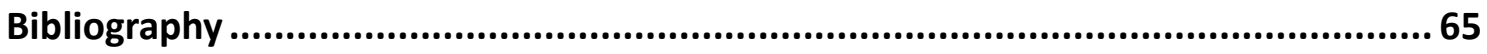




\section{List of Figures}

Figure 1: Beethoven's Piano Sonata, op. 111, 1st movement, mm. 25-26 ..................... 16

Figure 2: Beethoven's Piano Sonata, op. 111, 2nd movement, mm. 1-8 ….................. 18

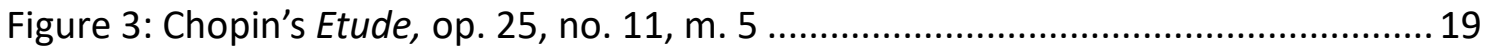

Figure 4-1: Appling Centrifugal force in Chopin's Etude, op. 25, no. 11, mm. 9-10........ 20

Figure 4-2: The physical breathing in Chopin's Etude, op. 25, no. 11, mm. 9-10 ........... 20

Figure 5: The Hierarchical retrieval schemes for the random digits and Bach's Italian

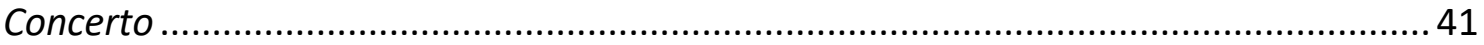

Figure 6: Schumann's Piano Concerto, 1st movement, mm. 12-15 ................................ 45

Figure 7: Mapping Music for Scarlatti's Sonata in G major, K. 2, L. $388 \ldots \ldots \ldots \ldots \ldots \ldots \ldots . . . . . . . . . . . . .47$

Figure 8: Mapping Music for Beethoven's Piano Concerto, op. 73, 1st movement.........49

Figure 9: The Keyboard geography for Beethoven's Piano Concerto, op. 73, 1st movement,

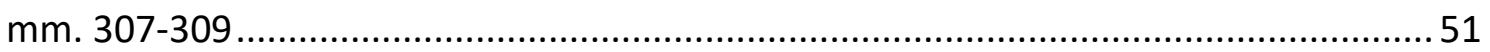

Figure 10: Ravel's La Valse mm. 369-371, 374-375, 378-379 .................................... 52

Figure 11: Rachmaninoff's Prelude, op. 32 , no. 5, mm. 7-8 ....................................... 53

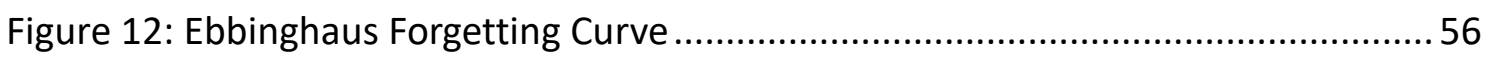

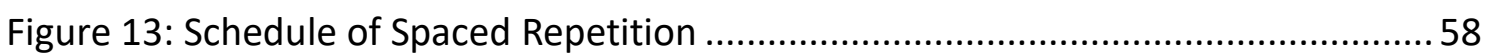

Figure 14: Personal copies of Rachmaninoff's Piano Sonata, and Bach's WTC II ...........60 


\section{Chapter 1}

\section{Introduction}

This research project focuses on selected ways of strengthening our memorization during the learning process, with the goal of minimizing inner stress and anxieties during our performances on stage. What inner work can we do to relieve our anxieties about performing without the score, while also preventing this fear from returning and blocking our freedom to connect with the music? In this chapter I discuss the importance of setting a goal each time we sit down to practice. Then I look at the risks of reverting to autopilot mode while practicing. Next, I consider the pros and cons of fast playing. The chapter concludes with some insights into learning to value our mistakes.

Consider an example from ordinary daily life: Do you remember the color of the shirt that an individual you talked with today was wearing? Sometimes I don't even remember what I was wearing today-or even right now. My teacher is several decades older than I am and, if I complain about forgetting something like that, he says, with the most generous smile, "It will get worse." Maybe? Or maybe not? We'll revisit this issue in Chapter 2.

Let's try again: How about trying to recall the order of the colors on Google's alphabet-letters logo? You can easily open the Google home page to see the answer. 
However, as pianists we spend hours in the practice room memorizing relatively complicated repertoire, much more complex than remembering the order of six colors on "G-o-o-g-I-e." I still fail to recall correctly those six colors, which I probably see every day. They're simple and obvious, but I haven't given them my full attention. Questions such as these relate to our ability to memorize when we focus. Our brain can in fact do more than we expect, when we pay attention. The challenge is often a matter of how to, rather than whether we can.

Nowadays, to most pianists, playing from memory in public is ordinary, unlike during the mid-nineteenth century, when performing in public without the score was criticized as a stunt that distracted attention away from the music. However, by the end of the nineteenth century, playing from memory had become standard procedure for pianists. Notwithstanding, whether one should play from memory or not has also become an interesting ongoing argument.

This topic has further given rise to many explorations of how pianists memorize music. There is abundant published research describing three primary ways in which pianists memorize music, including aural memory, visual memory, and motor memory. ${ }^{1}$ If you would like to explore books dedicated to memorization for

\footnotetext{
1 Hughes, Edwin. "Musical Memory in Piano Playing and Piano Study." The Musical Quarterly, vol. 1, no. 4, 1915.
} 
pianists, I recommended reading Piano Technique by Walter Gieseking and Karl

Leimer, ${ }^{2}$ How to Memorize Music by James Francis Cooke, ${ }^{3}$ and Musical

Interpretation by Tobias Matthay. ${ }^{4}$

\section{Having a Conversation with Yourself}

Before you place your hands on the keyboard and automatically revert to

autopilot mode while practicing, pause for a moment to ask yourself some questions:

Why am I here in the practice room? What is my goal today? And how soon do I

intend to reach the phase in which I feel performance-ready? Am I here in the

practice room due to guilt because my lesson is coming up soon?

Those questions might seem unnecessary; however, when we are on

autopilot mode, we tend to neglect some basic but important concepts. Too often,

we adopt an approximate style of learning and memorizing music. We assume that

we "know," but thinking this way can prevent us from learning more. ${ }^{5}$ In addition,

agreeing privately with yourself on setting a work deadline for reaching the

2 Gieseking, Walter and Karl Leimer. Piano Technique, Dover Publ. 1972

${ }^{3}$ Cook, James Francis. How to Memorize Music. Ann Arbor, MI: University Microfilms International, 1979

4 Matthay, Tobias. Musical Interpretation: Its Laws and Principles, and Their Application in Teaching and... Performing (Classic Reprint). Books for Libraries Press., 2015.

5 "The Power of Asking Yourself Questions." The Emotion Machine, 9 Dec. 2018, www.theemotionmachine.com/the-power-of-asking-yourself-questions/. 
performance-ready stage alleviates a lot of pressure and makes it easier to progress stress-free. It helps to remember your commitment regarding how much you want to accomplish. It is also true that "Quality is more important than quantity." ${ }^{6}$

Moreover, constantly asking ourselves questions while practicing increases our work effectiveness. Repetition in practice occupies much of the time we spend correcting mistakes and memorizing the material as we learn a new piece. But we need to be paying attention during repetitions, so that we practice the answers to our questions. Otherwise, we risk a mindlessness that entrenches the mistakes, rather than fixing them.

Too often a stroll through the practice wing of a music school lets us hear a practicing style that involves rapidly repeating a short passage without any pause between repetitions. Sometimes the pianist finally gets it right, almost by luck. Sometimes the passage is played with random fingerings, along with the same wrong notes as before. Sometimes a wrong note is "corrected" by the useless tactic of playing the offending single note multiple times as a punishment to the pianist and to the neighbors.

\footnotetext{
6 "Set the Deadline to Achieve Your Goals." 10 Aug. 2018. Web. 29 Mar. 2021. https://weidelonwinning.com/blog/set-the-deadline-to-achieve-your-goals/.
} 
In fact, according to James Francis Cooke's How to Memorize Music, we should give "Particular attention ... to exact repetition of the notes, the specific fingering, and definitely determined series of phrasing marks and expression marks."7

Moreover, "Doing the same thing over and over again in exactly the same manner forms habits of thought and action which, when properly employed, may become immensely valuable in memorizing." ${ }^{8}$ Each repetition is gradually built into our habits. Therefore, when the day comes for the final stage of performance, the last thing we want is the habit of repeating mistakes, confused fingerings, or memory slips. "With correct repetitions certainty of performance is developed and confidence created." ${ }^{\prime 9}$ Repeating a passage is one of the common ways of practice; but, when repetition becomes mindless, more than likely we start to rehearse both mistakes and the inanition of music that resulted in building a bad habit or possibilities of selffrustration and regression. To me, practicing piano is far beyond just playing the piano, but a mindfulness of learning in our daily life. One of the teachings by Zen Master Thich Nhat Hanh" ${ }^{10}$ says "Most people are afraid of suffering. But suffering is

7 Cooke, p. 59.

8 Ibid.

9 Cooke, p. 60.

10 Thich Nhat Hanh (1926-present) is a Zen Master, "a global spiritual leader, poet, and peace activist, revered around the world for his pioneering teachings on mindfulness, global ethics and peace." https://plumvillage.org/about/thich-nhat-hanh/ 
a kind of mud to help the lotus flower of happiness grow. There can be no lotus

flower without the mud." ${ }^{11}$ Cannot this be applied to music as well?

\section{Do you feel good about playing music?}

\section{Or does playing music make you feel good?}

These two sentences might seem to be the same. However, in the former sentence, "you" comes before the music, while, in the latter sentence, the music comes first, allowing us to arrive on its flow and see the beautiful view. The former concept does not mean you are any less skillful as a pianist than the latter; similarly, the latter does not mean that you can suddenly play a difficult masterpiece in a day. In fact, when a pianist's hunger is for outside appearance, such as the need for audience attention or the need to exude a sparkling aura, or how the arms will fly in the air at the end of the last piece in the program - then, something is indeed missing.

11 Hanh, Thich Nhat. No Mud, No Lotus: The Art of Transforming Suffering. Parallax, 2014. 


\section{Soaking in a self-sweetness jar}

One might feel that the visual aspect is important in piano performance as

well. As I discuss above, playing music makes us feel good, giving us happiness as we are blessed to share beauty with the audience. Hence the feelings and performance gestures or even facial expressions should firstly come from deep inside our heart. The "outside" will naturally express the performer's love of music, certainly not the other way around. Lang Lang, ${ }^{12}$ originally from China, is one of the world's bestknown concert pianists. He has brilliant technique, has performed countless concertos with world-famous orchestras, and has published books and CDs. Yet after watching some of his piano-lesson videos, I felt a little bit lost. For example, in one private lesson, Lang is teaching a child who undoubtedly has very impressive piano skills for his age. ${ }^{13}$ In the video, Lang is enthusiastically patting the child's shoulders and passionately reminding him, "I can't hear it! It has double strong!" 14 while the student played that particular short passage faultlessly on the piano. His intense commenting about fortissimo actually sounds louder than the piano playing, so the boy can't hear clearly while he is playing.

\footnotetext{
12 Lang Lang (1982-present) a well-known Chinese concert pianist who has performed in China, Europe and the United States. https://www.langlangofficial.com/ 13"郎朗教小朋友上钢琴课太搞笑了太有激情了." [Lang Lang teaches piano with excessive humor and passion.] YouTube. YouTube, 17 Nov. 2019. Web. https://www.youtube.com/watch?v=WJlivg4x7rg 14 I.e., fortissimo.
} 
Watching this teaching video provoked my concerns: Does the pianist hear his music along with the dynamic expressions? Or does the teacher not hear his own expected level of fortissimo from the child? (See chapter 3 for more discussions regarding this topic.)

Secondly, at the end of the video, Lang is guiding this young student to throw both his arms into the air high enough to let everyone else notice that it is the end of the performance. Is this necessary? What is the balance? Or is there a balance?

"There is a way to again be in real time with the universe, but it is not through force, imagination or manipulation. It is by finding your true Self. When you do, you will not need to manipulate life, it will simply flow."

$--M o o j i .{ }^{15}$

\section{Auto-run-through mode}

The danger of auto-mode practicing is that our insight into the music slackens at that moment, so that inevitably our practice becomes a gymnastic exercise. Yet auto-mode practice itself becomes a bad habit, reinforced by believing that the goal of piano playing is to be able to play without thinking. According to Tobias Matthay, automatic practice is useless, harmful musically, and even detrimental to technique

15 "Mooji - Mooji." Mooji.org. Web. 16 Nov. 2020. https://mooji.org/mooji 
as well. "It must be constantly insisted upon, that if we try to make the piece, or study or technical exercise 'go by itself', this, so far from being 'practice' is indeed the opposite - it is un-practice." 16

Moreover, the automatic playing discussed above leads to the question of whether we are actively listening while we practice, instead of just hearing what we project after we play. As pianists we have a rich repertoire of beautiful compositions for our very expressive musical instrument, which also allows colorful pedaling. The risk is that we tend to soak ourselves in this sweet jar and let it "go by itself"; then we most likely forget what is actually happening at each moment or between the notes. According to Matthay's idea, we do not "listen" unless we analyze what we play. He also gave an example of observing the pattern of a curtain covering a window or an object outside of the window. Whichever object we choose to observe, we give it our focus and awareness. These are "everyday" or "normal" things, much like the objects considered in the first two questions that I asked at the beginning of this paper: "Do you remember the color of the shirt that a particular person you talked to today was wearing?" and "What is the order of the colors on Google's letters of the alphabet?"

16 Matthay, p. 5. 
"The things we do not thus analyze we also do not observe - and this,

although the light rays do pour in upon us all the time, both from the curtain and

from the objects beyond it!"17

Another result of automatic practicing with both advantages and

disadvantages at the same time is the gradual build up of one type of memory:

Kinaesthetic memory, which is also called "muscle" memory, "motor" memory, or "automatic" memory. James Cooke relates in his How to Memorize Music an account of how he witnessed a miraculous case of Kinaesthetic memory in New York. A world-famous virtuoso pianist named Alfred Reisenauer, ${ }^{18}$ who had been a pupil of Franz Liszt, was absolutely intoxicated; nonetheless, he sat down on the piano bench and started playing a highly difficult masterpiece by Liszt ("La Campanella") with perfectly faultless playing until he completely lost his control. ${ }^{19}$ "The fingers seemingly go on playing with little conscious control, just as one winks without realizing it."20 Alfred Reisenauer probably did not even remember that he was drunk

17 Matthay, p. 6.

18 Alfred Reisenauer (1863-1907), a German pianist. "He was another of the pupils of Franz Liszt and contemporaries of Johannes Brahms who lived to record, and a very successful and highly regarded pianist, particularly in Germany and Russia. He was also an important teacher, serving at the end of his career as the director of the Leipzig Conservatory."

https://www.forte-piano-pianissimo.com/Alfred-Reisenauer.html

19 Cooke, p. 24.

20 Ibid. 
or that his fingers flew around the keyboard without any conscious control; yet his remarkable kinaesthetic musical memory so surprised Cooke that he said "It was an unforgettable manifestation of a human being...."21

Meanwhile, it is indeed helpful to develop our Kinaesthetic memory. Generally, the more different types of memory we engage skillfully, the more secure we are. If performers depend too much on one way of memorization, more than likely they are inviting a memory slip to happen. Kinaesthetic memory seems especially susceptible to this danger.

There is a Chinese proverb that says, "One chopstick is easily broken, while a bundle of chopsticks is not." For a pianist, each performance is an adventure that involves risk, in part because the piano at our performance venue will probably be an unfamiliar instrument that is provided by others. Supposedly we will have a chance to get to know the piano's personality and quirks as much as we possibly can within a short rehearsal time. This requires that we constantly learn and adjust our feeling of physical touch, as any given piano may have any given number of variables in touch and sound from our usual practice instrument. Under such circumstances the Kinesthetic memory becomes less reliable. Even if one could carry their own 21 Ibid. 
instrument on stage, like a violinist or a cellist, it would be almost impossible to avoid any possibility that unfavorable things might happen under feelings of high pressure or additionally from the environment, such as the temperature of the concert hall being too cold, audience members making sounds, or even the piano itself making distracting noises. Relying on one type of memorization is undoubtedly taking a risk during such uncertain, surprising situations. If we memorize diligently (see chapter 2) as early as we can, from day one of learning a new piece, or even when we resurrect our old repertoire from previous study, we can greatly strengthen our security in performance in either case. In the case of old pieces that may not have been learned properly or sufficiently, we need to be extra careful that our old habits from musclememory learning will not take over again. Applying effective memorization techniques is a great remedy for that.

\section{$\underline{\text { I can play faster than you, you, and you }}$}

One of my university colleagues shared a story with me about his practice-room observations. One day when he had just settled into the practice room to begin work, he heard his neighbor passionately practicing Chopin's Etude, op. 25, no. 10 (Octaves). My colleague started to warm up with a few minutes of scales. After that, he began practicing Chopin's Etude, op. 25, no. 6 (Double Thirds) in a very comfortable tempo. A few seconds after he had just finished his first run-through of 
this etude, he heard this neighbor suddenly stop working on the etude in octaves, only to start playing the same etude he had just played, but at a frantically high speed, much faster than he had played it. After that one-time high-speed ride, the neighbor went back to working on the Octave Etude. Was this an attempt to one-up my colleague? In pursuit of velocity, one is inclined to neglect the beautiful things that happen in the music.

“Humans are creatures of habit - form good ones and they'll serve you well. Practice is a bit like prayer - it requires focus and a listening soul. If your mind is occupied with inner chatter unrelated to the movement of your fingers, you may be doing what I call negative practice - at best unproductive, often destructive." 22

When one only thinks about playing faster than others or even faster than composer's idea, more than likely one is not making music or connecting to loved ones; instead, one is making unmusical "sound," much like a high-speed typist. Whether it comes to speed or volume, a bombastic style of practicing does not help in our listening; it also dangerously increases the possibility of injuring our hands. Instead, practicing even a fast piece like a nocturne, as suggested by Gieseking and Leimer, "is necessary for the absolute and exact rendition in the Cantilena style. The inner warmth and feeling can be increased, the delivery becomes more ardent, if the

22 Wolff, David Michael. "Practicing." The Carolina Philharmonic. The Carolina Philharmonic, 14 Dec. 2015. Web. 18 Nov. 2020. https://www.carolinaphil.org/zen-and-the-art-of-piano/practicing. 
absolute tone lengths are observed." ${ }^{23}$ Moreover, there is benefit from practicing slowly enough that our brain can concentrate either first on basic fingerings or correct notes, and practicing of notes within the dynamics of piano and pianissimo, until the notes are correct and dynamically equal. With this practice style, we will hear more subtle degrees of dynamics. "They learn to discriminate between loud and soft tones. They conceive the exact lengths of tone and feel their values. It is hardly deemed necessary by many to study in this technical manner, yet it has an essential effect upon the ear." ${ }^{24}$ In the exercise just described, speeding up the tempo happens little by little, ideally within a short passage.

To me, velocity is the last thing to be attempted. If we wholeheartedly chase speed and fast fingers, but with careless attention to the beautiful music that happens between the notes, more than likely our understanding of the music will only be approximate, with memorization incomplete, inviting memory slips to happen on stage. Edwin Hughes observes, in his article "Musical Memory in Piano Playing and Piano Study," that "It is so easy at a certain point to leave nine-tenths of the work to the purely reflex action of finger memory. This is one of the worst hindrances to the acquisition of sureness in memory work." ${ }^{25}$ According to Cooke,

\footnotetext{
${ }^{23}$ Gieseking and Leimer, p. 90.

${ }^{24}$ Gieseking and Leimer, pp. 90-91.

25 Hughes, pp. 592-603.
} 
"The general form of the figurations and the hand positions in such playing [fast playing] may be under mental control, but the actual impulses which direct the fingers in rapid performance come from nerve centers nearer to the fingers than the brain. Be aware of this habit! It may be fatal to you on the concert platform."26

\section{$\underline{\text { Hey, playing faster does help! }}$}

Indeed, developing finger velocity is an essential skill for pianists, but it is crucial to start with a deeper layer: the musical line connecting the notes and the dynamic layers within the musical flow. Practicing with maximum connection from one note to the next note is a very deep practice. Yet, in working to increase speed or technical skill, technical polish will not happen by focusing only on the deeper level of musical groupings. What is needed is both attention to the surface layers (technique) and the deeper layers (musical ideas and flow). When playing fast, one of the challenges is how we get to a synergy of these elements. Hence, too much in either directiontechnical skill or musical grouping-is dangerous.

Practicing by applying a repeated-note method is one of many ways to increase speed, evenness, and memory security. Repetition involves not just repeating the note, but bears the caveat that it has to feel EASY. Everything might sound great, but

\footnotetext{
${ }^{26}$ Cooke, p. 96.
} 
there should also be a sense of effortlessness. For example, in the first movement of Beethoven's Piano Sonata in C minor, op. 111 (see figure 1):

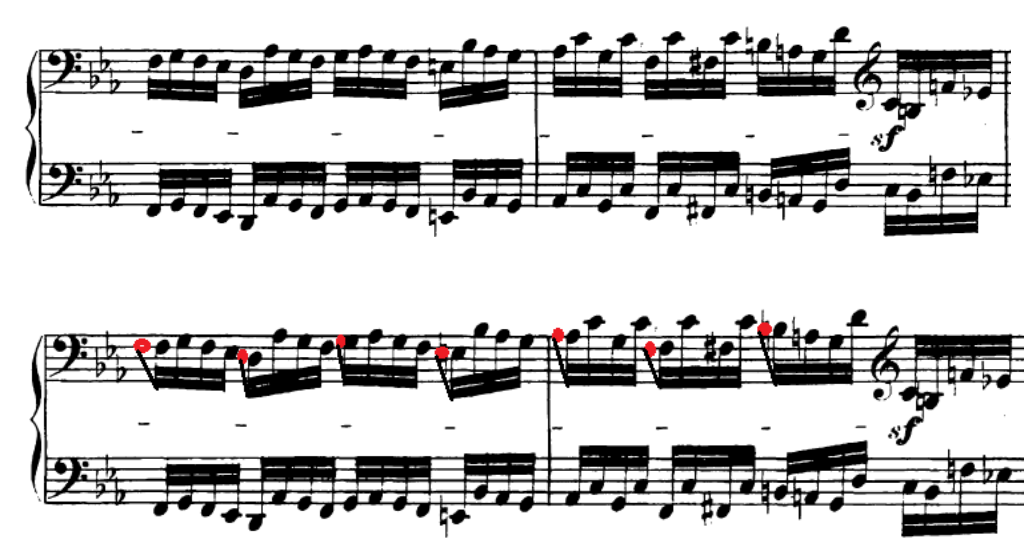

Figure 1: Beethoven's Piano Sonata, op. 111, 1st movement, mm. 25-26

This repetition exercise involves playing predetermined notes twice (i.e., at double speed), which also means connecting to the next note in half the time, increasing memory, speed, and evenness.

On the other hand, we often hear that "slow practice" is one of the indispensable secret ingredients of performing securely. Especially when the passages involved are dazzling, the more we practice slowly, the more we feel secure. However, practice at a fast tempo also benefits in some ways, such as helping to gauge musical flow, physical movement, and feeling the pulse. Perhaps we spend a 
lot of time in the practice room shaping the melodic line note by note or phrase by phrase beautifully. Still it is easy to neglect the bigger picture revealed in the piece as a whole. What are the dynamics or musical flow within those phrases, or what about the dynamic layers within those sections?

Consider for example, the second movement of Beethoven's Piano Sonata, op. 111. Once we feel we have learned this opening theme thoroughly and know our approximate performance tempo, a suggested next step of practice could be trying to play this theme twice as fast as our ideal performing tempo, perhaps leaving out the inner voices, just playing the top voice and bass if it feels safer to do so. Undoubtedly this is not a test of your ability to play fast. Instead, playing this lyrical opening theme at a faster tempo is to hear a bigger picture. At a much faster tempo, how would you shape the bass line? What are the relationships among the top notes? Playing faster helps us to hear the musical line much more clearly, determine the direction of musical flow, and explore how we would like to shape it. (See figure 2.) 


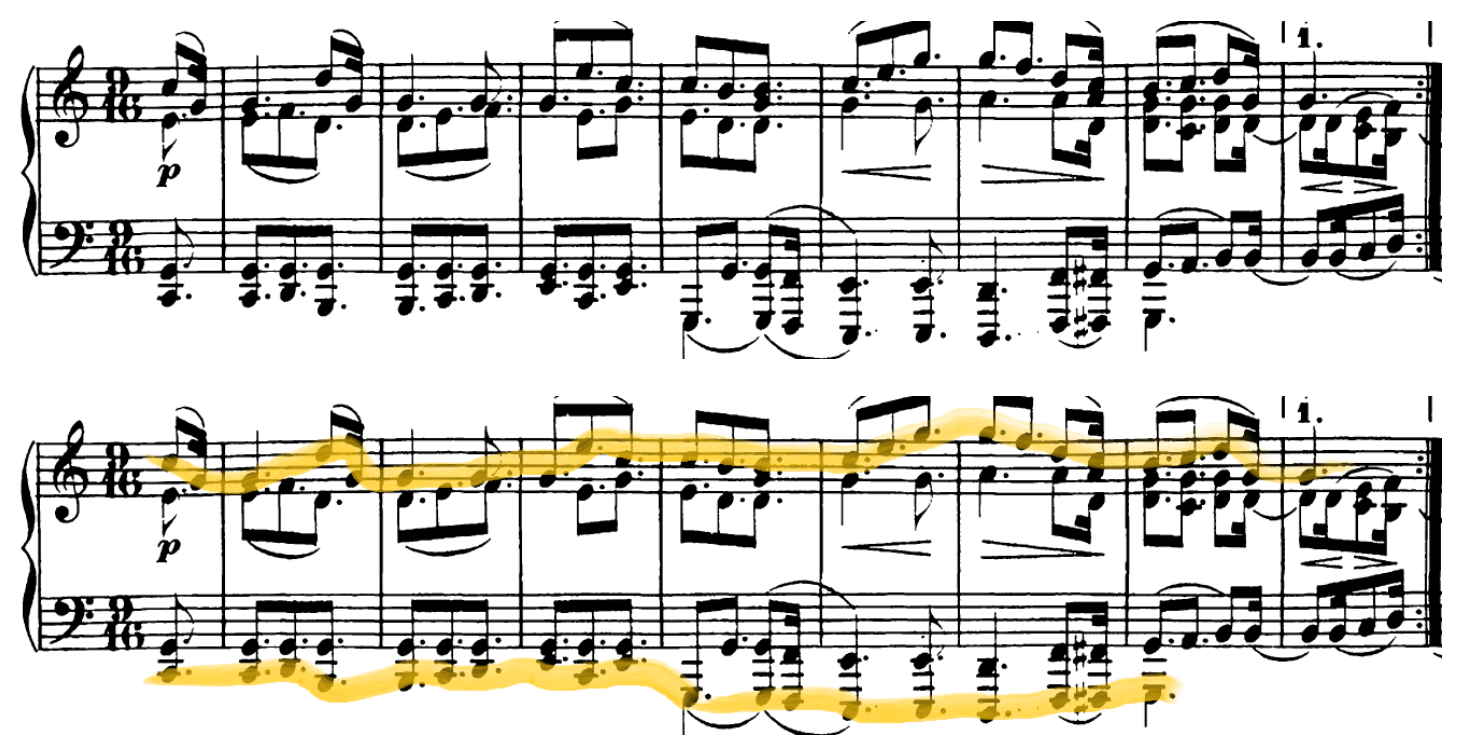

Figure 2: Beethoven's Piano Sonata, op. 111, 2nd movement, mm. 1-8

Another benefit of practicing at a faster tempo is to understand our hand movements in order to ease physical tension. When we think of working on any technically demanding piece, our preferred choice of practice tempo-at first our only choice tempo-wise-probably tends to be slow practice. Correct notes respond well to slow practice. However, when we practice brilliant running passages, we need to pay closer attention to our physical relaxation. For example, consider Chopin's Etude, op. 25, no. 11, often referred to as the "Winter Wind." Let's look at ways of approaching this piece, with the intent to incorporate relaxation into a practice routine. 

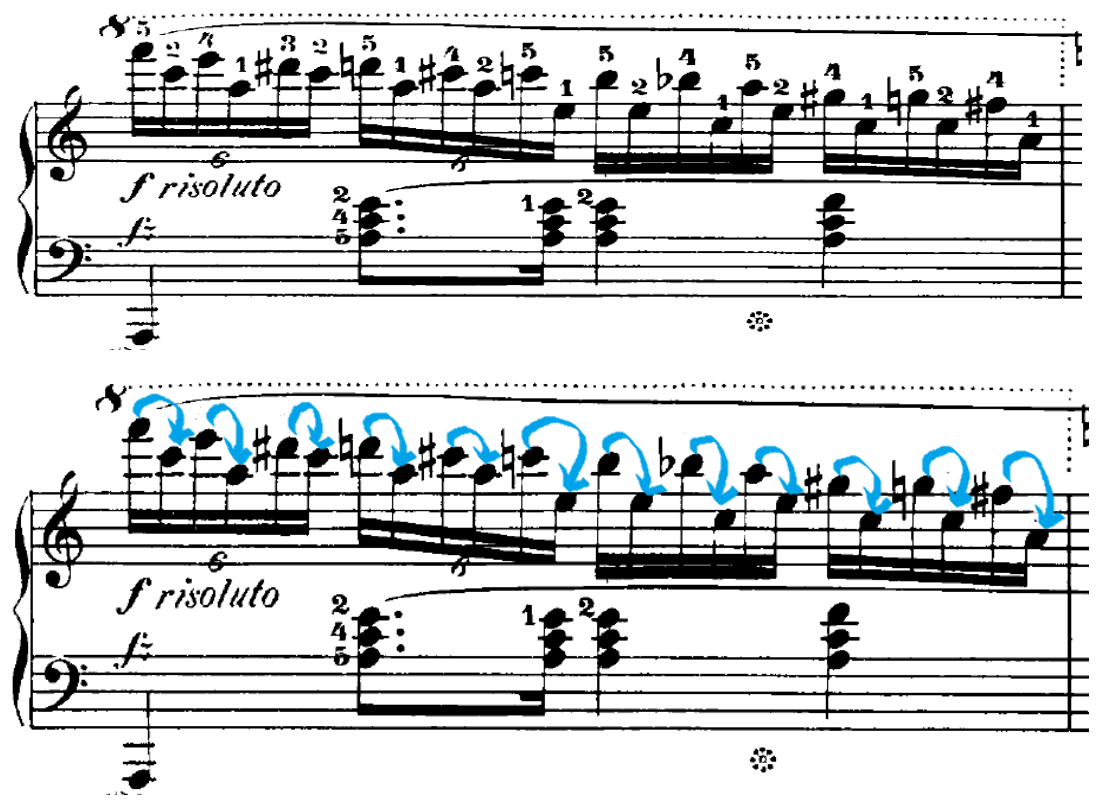

Figure 3: Chopin's Etude, op. 25, no. 11, m. 5

First of all, even though the right-hand part is written in even sixteenth notes,

for this approach we can start by grouping two sixteenth notes together, starting

from the higher one in each pair and ending with the lower note. To execute these

two notes, (see figure 3) imagine we are turning a doorknob, paying attention to the

rotation of the forearm. Trying this movement first on the fallboard, our hand must

be completely relaxed. After experimenting with this movement a few times, open

the fallboard and play on the keyboard as it is written, along with the "doorknob"

rotation of the hand and arm. Our fingers indeed must have support, but not with

tightness or dinosaur-claw-style hand gestures. Secondly, in order not to risk injury to

our hand, we always need to be aware of relaxation. Even when practicing at a 
tempo that is faster than our ideal performance speed, we would do well to

remember that we are not competing to see whether we are able to play it as the

"Winter Hurricane." Instead, as the tempo increases, we must continue to feel the

physical movement and relaxation together. At the same time, it pays to be aware of

where the physical movement changes direction and apply "centrifugal force" in the

passage (see figure 4-1) and where the physical breathing moments are (see figure 4-

2).
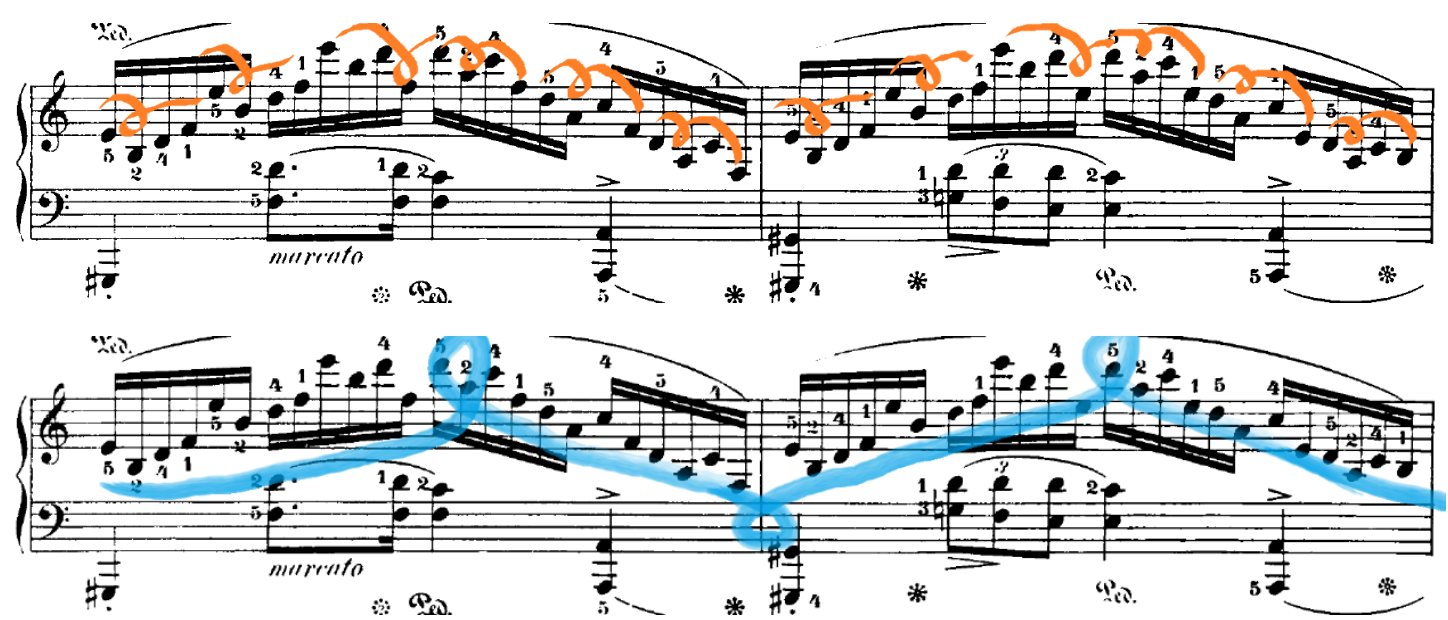

Figure 4-1: Chopin's Etude, op. 25, no. 11, mm. 9-10

(Orange color: small centrifugal force; Blue color: bigger centrifugal force)

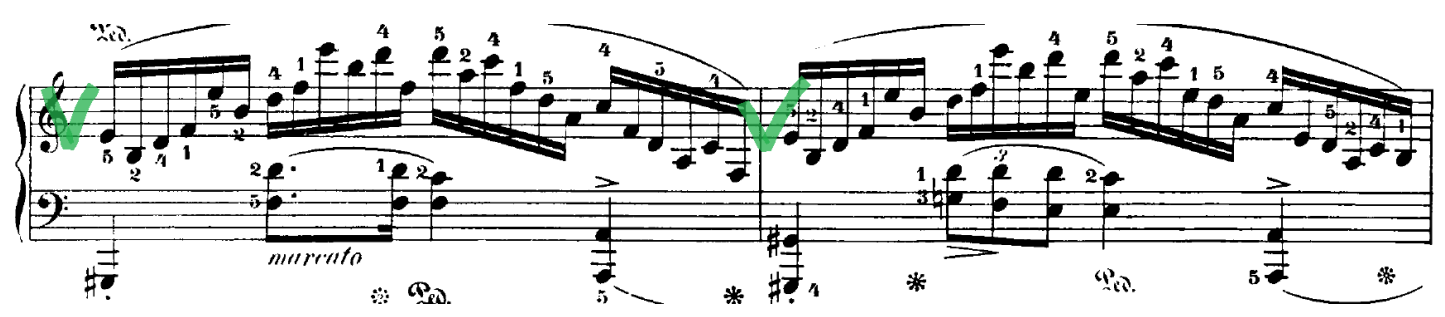

Figure 4-2: Chopin's Etude, op. 25, no. 11, mm. 9-10 
Surprisingly, you may notice that playing a challenging piece faster is actually not as difficult as anticipated. It begins to feel easier and stronger. A pianist can apply finger independence to a passage and achieve changes in expression through carefully calculated finger work, building a crescendo note by note as each successive finger stroke gets stronger. Yet there is another way, which benefits from natural application of arm weight, circular motion and centrifugal force. If we apply what is natural to our bodies, we can use this natural intelligence to shape a phrase or a series of notes rather than having to make independently calculated finger strokes. Because our application of weight for projecting the sound comes from a different resource rather than just the hands themselves, the former is natural physical movement, fluid and efficient as a bird riding the air currents through canyons and between high mountains.

"When the musician can forget his technical obstacles and think entirely of the interpretative, musical message, he has taken a vast step ahead in his musical life." 27

\section{$\underline{\text { Mistakes are our friends }}$}

Friends might inquire, "How was your recital?" Sometimes the answer might be, "I did a bad job, because I played some wrong notes." We might often hear such answers from students or we might at one time have said such things ourselves after

27 Cooke, p. 61. 
a performance. Sometimes making mistakes might deflate our confidence on stage,

letting the rest of program become a miserable experience. But after a "bad"

performance, it is actually interesting to analyze why the "bad" moments occurred.

By collecting those "bad-valuable" experiences, we may come to see what we can

learn from them. Once my pipa ${ }^{28}$ teacher suggested to me in a lesson that "The first

thing to do after you wake up is to play your instrument, in order to identify the

sections you need to work on even more." ${ }^{29}$ Checking for those surprising, hidden,

or even self-satisfied bits is essential in our practice. It surely will impact our

performance either in the quality of the playing or in our mental state. Some pianists

might say to themselves on stage, "Luckily, I survived!" or even "I fooled everyone!"

because they did not make any obvious mistakes. In such circumstances, though, a

lack of thorough preparation has prevented them from enjoying and connecting to

the music on stage.

\footnotetext{
28 ”The Chinese Pipa (琵琶), a four-string plucked lute, which descended from West- and CentralAsian prototypes and appeared in China during the Northern Wei dynasty (AD 386-534). Originally it was held horizontally like a guitar, and its twisted silk strings were plucked with a large triangular plectrum held in the right hand. The word pipa describes the plectrum's plucking strokes: pi, "to play forward," pa,"to play backward." Moore, J. Kenneth. "The Pipa." In Heilbrunn Timeline of Art History. New York: The Metropolitan Museum of Art, 2000-.

http://www.metmuseum.org/toah/hd/pipa/hd_pipa.htm (October 2003)

29 Pipa teacher: Du Jie-Ming，杜潔明
} 
Did we somehow make the same mistakes in performance as last time? For example, upon scanning our mistakes and analyzing them, we could realize that there had been a recurring memory slip. But noticing where we often have a memory slip is the key to fixing our practice in the future. Perhaps one often has a memory slip during a particularly rapid passage, or a slow lyrical section, or a lefthand bass line? That could mean our habit of practice was not clear enough, that it probably has been just an approximate memorization and hearing. Mistakes are our friends - they show us where we need to give more loving attention in our work. Moreover, if and when we make mistakes on stage, we should keep our mind calm and simply enjoy the rest of the music. Whom we are connecting with is more important than those little mistakes that happen on stage.

"To play a wrong note is insignificant; to play without passion is inexcusable." 30

"All that anyone should ever venture to do, is to listen reverently and without question to his - the artist's - supposed, God-given messages!"31

"To have faith is to trust yourself to the water. When you swim you don't grab hold of the water, because if you do you will sink and drown. Instead you relax, and float." 32

\footnotetext{
30 Attributed to Ludwig van Beethoven, in "About." Viennese Masters Orchestra Invitational. 30 Mar. 2021. Web. 31 Mar. 2021. https://viennesemasters.org/about/

31 Matthay, p. 13.

32 Watts, Alan. "Quotes." Alan Watts Organization. 21 Mar. 2021. Web. 31 Mar. 2021.

https://alanwatts.org/quotes/.
} 


\section{Chapter 2}

In this chapter I discuss the memorization process by first introducing the reader to techniques such as the Memory Palace, devised by memory pioneers in ancient Greece. I then look at how this applies to the learning process. Lastly, I discuss the important role that forgetting what we learn plays in our ultimate success at memorization.

\section{Memorizing without effort}

You may have heard the myth that a goldfish's memory only lasts three seconds, and that after three seconds everything is a whole new world to them. Therefore, they are always happy just being in their tiny fish tank. But science has actually proven that a humble goldfish has a memory span of up to five months. ${ }^{33}$ In a similar vein, we may have heard or believe that the older we are, the worse memory we will have. But in fact, according to a study from Harvard Women's Health

\section{Watch,}

When significant memory loss occurs among older people, it is not due to aging but to organic disorders, brain injury, or neurological illness. Most of the fleeting memory problems that we experience with age reflect normal changes in the structure and function of the brain. These changes can slow certain cognitive processes, making it a bit harder to learn new

\footnotetext{
33 "Do Goldfish Really Have a Memory of 3 Seconds." Social Beat. 28 Jan. 2021. Web. https://socialbeat.in/youtube-seo-tips/wp-content/uploads/u99srn6/b5fcc0-do-goldfish-really-havea-memory-of-3-seconds
} 
things as quickly or screen out distractions that can interfere with memory and learning. ${ }^{34}$

Our incredible brain can do more than we expect; there is no "evidence that would limit the ability of motivated and healthy adults to achieve exceptional levels of memory performance given access to instruction and supportive training environments." 35

Is there any way we can possibly let memorization become less of a struggle and less painful? I still remember a time when I was little and my mother took me to a conference at which the teacher let us use our own imaginations while he was introducing a series of images. After he described the series one time, we had all successfully memorized the order of the planets in the solar system in less than a minute without a painful memorizing process. We also discovered we did not just remember their order away from the sun, but also backwards from the outermost planet to the innermost. Now, 20 years later, I still remember vividly how I visualized them and can still remember the order of the planets. The point is not that I am proud about my ability to memorize. In fact, this example just shows that

\footnotetext{
34 Publishing, Harvard Health. "Preserving and Improving Memory as We Age." Harvard Health. Web. 26 Nov. 2020. https://www.health.harvard.edu/newsletter article/preserving-and-improvingmemory-as-we-age.

35 Hoffeld, David. "Your Brain Can Do More Than You Think It Can, Says Science." Fast Company. Fast Company, 17 Feb. 2017. Web. 26 Nov. 2020. https://www.fastcompany.com/3065915/your-brain-cando-more-than-you-think-it-can-says-science
} 
memorization can be effortless and fun-and, more importantly, that it lasts longer than we expect.

I would like to invite you to try memorizing the list below of ten random items by scanning it three times. After that, try to recall these items, preferably in the order they appear on the list, or even backwards.

\begin{tabular}{|l|l|}
\hline No. & Item \\
\hline 1 & Baby \\
\hline 2 & Mountain \\
\hline 3 & Fire \\
\hline 4 & Toilet \\
\hline 5 & Beethoven \\
\hline 6 & Ice cream \\
\hline 7 & Screw \\
\hline 8 & Comforter \\
\hline 9 & Snake \\
\hline 10 & Sunglasses \\
\hline
\end{tabular}


For most of us, this task might seem a little bit challenging to memorize in such a short time by only scanning; however, that difficulty invites us to consider how to complete the task successfully, instead of asking ourselves why we can't do it on the first try. You may have your own methods during the process, such as memorizing the first letter, grouping, seeing the list like a photo in your mind, or creating a story to link all the items together, etc. The last one probably stays in our memory longer than other methods, but it takes more time to build a "reasonable" story. Then how could we memorize these items more easily and in a shorter time? The key is "connection." For example, we could join two items together in one sentence, instead of creating a "story." Please consider the sentence suggested below for each pair of terms and then look at the accompanying illustrations.

"A baby is crawling on the mountain."
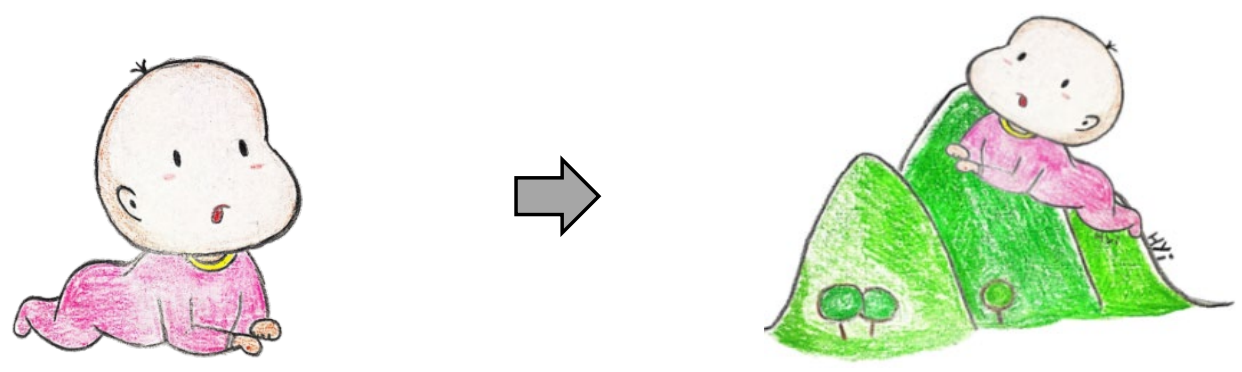
"The mountain is on fire."
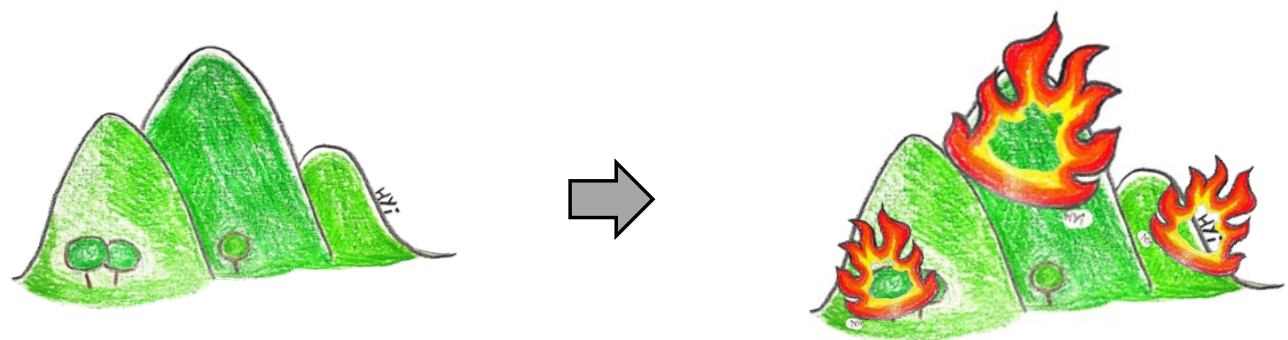

"Use Toilet water to put out the fire."
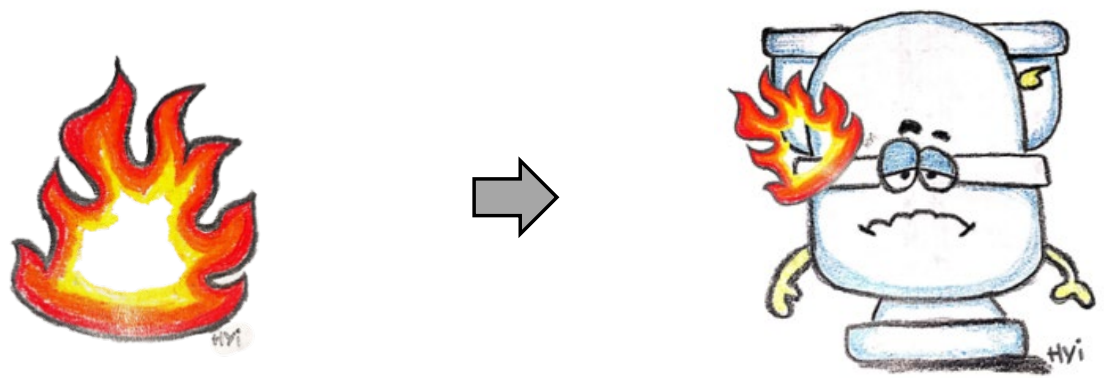

"Beethoven is sitting on the toilet."
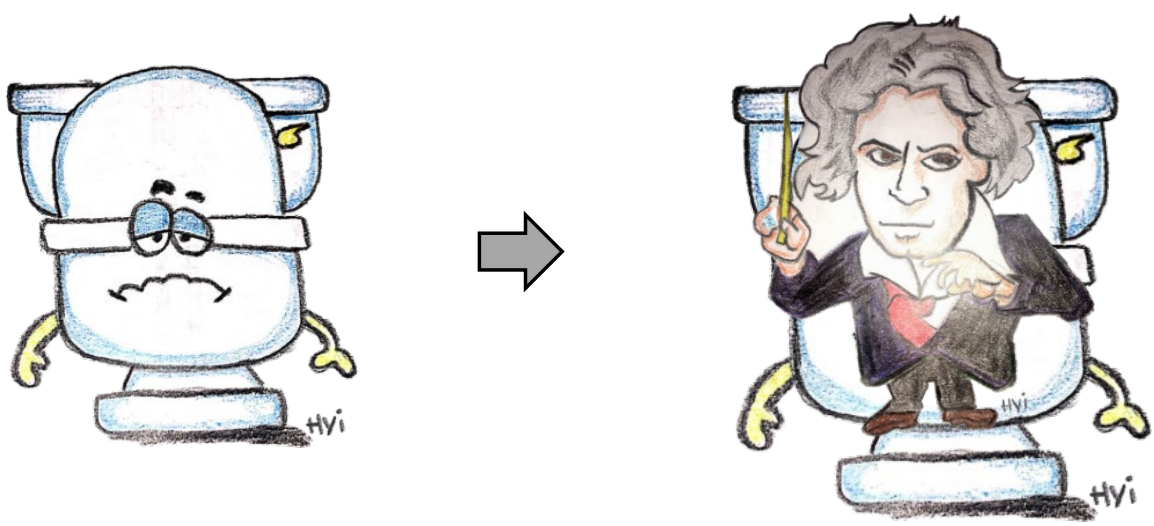
"Beethoven is eating ice cream."
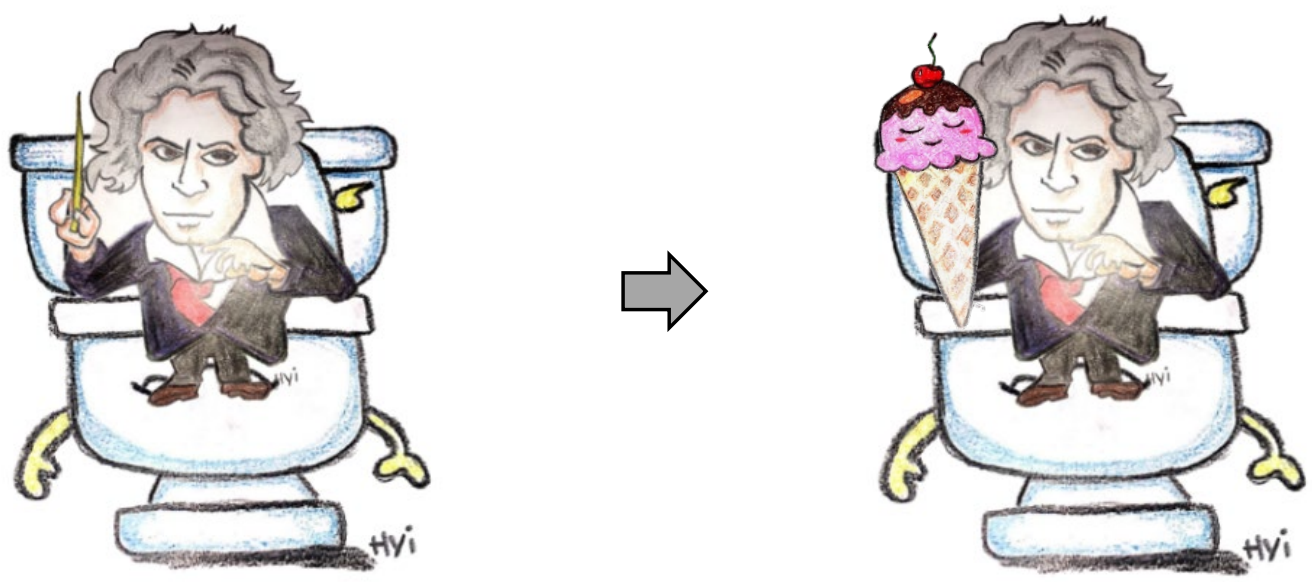

"The ice cream has screws in it!"
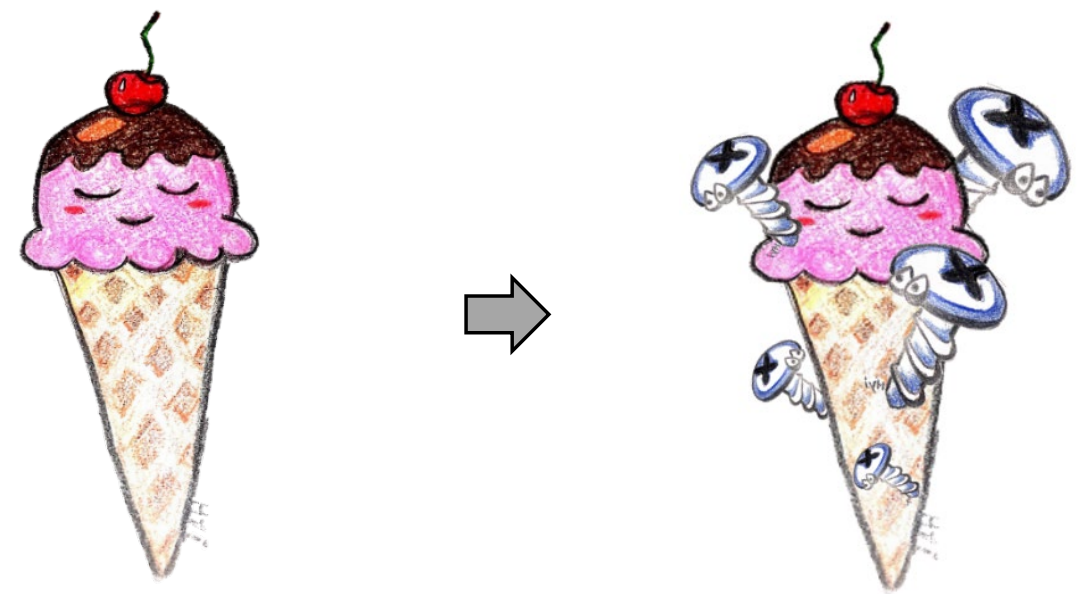

"Beethoven is eating screws ice cream in the comforter."
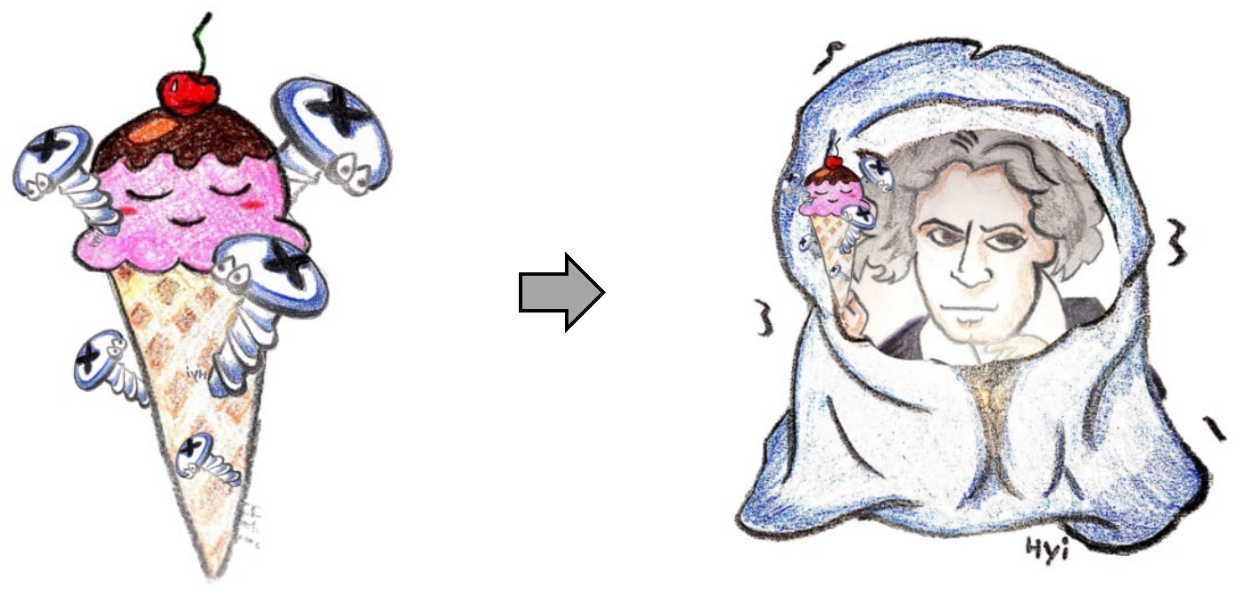
"Snake is inside the comforter."
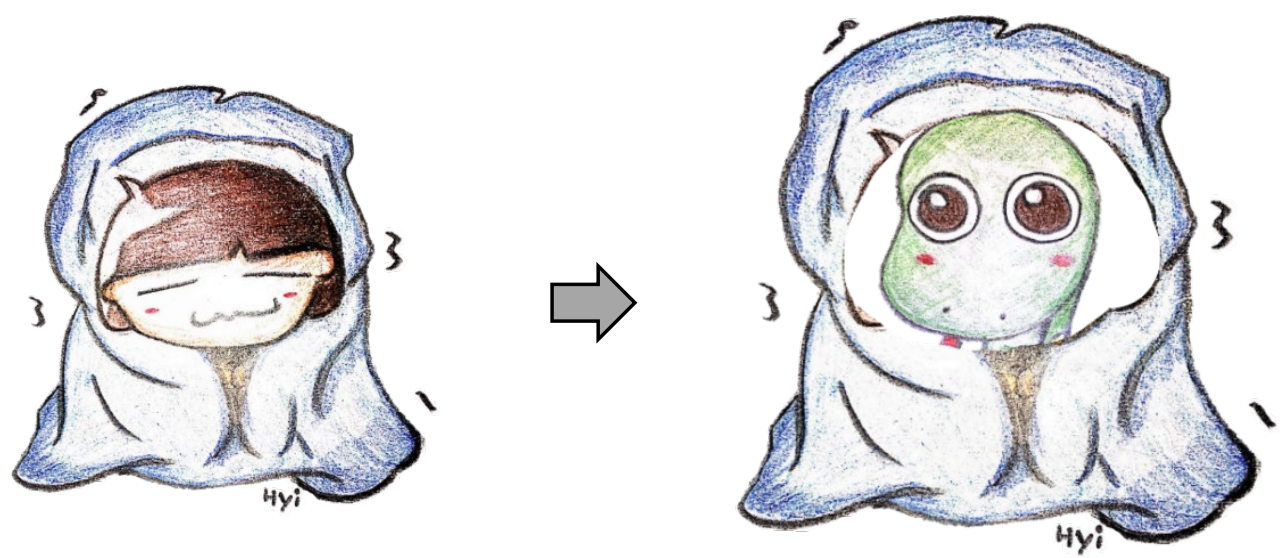

"Snake is wearing sunglasses"
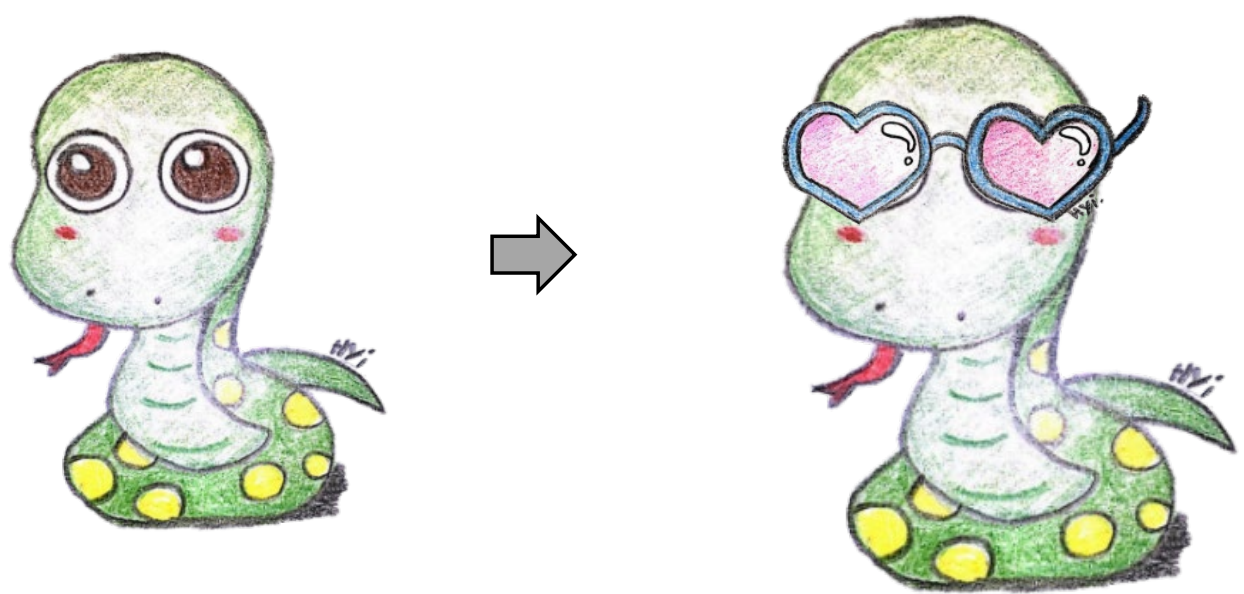
After following the series of illustrations shown above, most people can remember nearly every random item from the list and even recall the items backwards effortlessly. You don't need to have drawing skill, provided that you come up with your own images. The items can be real, from your own experience, or they can come from your imagination.

However, when picturing them, we are not just stacking two unrelated items together. If they don't "connect," we are merely forcing our brain to memorize by rote yet another series of unrelated items. By contrast, our real goal is to create a situation that links the two items, creating meaning. Creating meaning in this way makes the task easier and more enjoyable than brute-force rote memorization. Instead of viewing random items, we try to visualize them and give them a simple sentence that links each successive pair. The sentence does not have to be "realistic." For example, think of our snake wearing sunglasses or the ice cream replete with screws. While such concepts don't apply very much to real life, they are highly memorable. Memorizing effortlessly? You just made it happen! 


\section{Memory Palace}

There is an ancient concept known as the "memory palace." 36 The idea is to create your own imaginary palace (or just a room) with select locations inside, such as a table, trash can, piano, laptop, etc. These will become your selected storage areas. Once you have solidified your room and its storage capabilities, you can then put it to use for all the items in your life that you need to memorize or retain for future access. Retrieval occurs by consciously making a journey through your palace, accessing specific storage sites for specific information.

My first experience creating and using my own memory palace was fascinating. I successfully memorized 100 selected images after just one visualized run-through. I built ten rooms in my imaginary house and in each room I established ten different selected storage areas. Over the next two days I tested my recall of those 100 images and, to my own surprise, I could still remember them faultlessly.

For advanced-level retention, you can keep expanding the dimensions of your palace. For example, if you create another ten rooms on the second floor of your house, you

\footnotetext{
36 The "method of loci" - "Sometimes called the Memory Palace-is a systematic memory technique that dates back to the days of ancient Greece. The system remained prevalent through the Middle Ages and the Renaissance. Educators used it as did orators, the better to remember aspects of long speeches during a more attentive age." Handwerk, Brian. Neuroscientists Unlock the Secrets of Memory Champions. 13 Mar. 2017, www.smithsonianmag.com/science-nature/why-you-can-train-your-brain-memory-champion-stillforget-your-car-keys-180962496/.
} 
will then have a total of 200 selected storage areas in your palace. Adding a third floor-or even additional houses-allows continuing the expansion and retention capacity.

Those 100 selected storage areas that I just tried are merely "containers"; they are not what you are trying to remember on your list. Of foremost importance is the need to have a good foundation to our Memory Palace. Most experts suggest that the beginner needs to keep reviewing his or her selected storage areas and the layout of the memory palace itself so that, when we need to store something and remember it later, the entire structure is secure.

The eight-time World Memory Champion winner Dominic O’Brien (b. 1957) was able in less than three minutes to memorize the order of playing cards in a shuffled full deck and to recall the order of fifty two playing cards after just viewing them one time. ${ }^{37}$ Many great memorizers like him can be found, yet most of them shared in their interviews ${ }^{38}$ that they use a system such as Memory Palace or a related idea such as “Dominic System” (Person, Action) or "PAO system” (Person,

\footnotetext{
37 Dominic O'Brien was born in 1957; he is an eight-time World Memory Champion winner. He devoted his time to developing his mnemonic techniques, called the Dominic system. He also has published several memory-related books. https://peakperformancetraining.org/.

38 Kristensson, Sophia. "World Champion Teaches You How to Remember." Chalmers. 05 Oct. 2018. Web. 01 Apr. 2021. https://www.chalmers.se/en/news/Pages/world-champion-teaches-you-how-toremember.aspx. See also Dominic O'Brien In an interview with CNNMoney Switzerland's Amanda Kayne: https://www.youtube.com/watch?v=ACw5YVgg4lc\&ab channel=ArchiveTV.
} 
Action, Object), which are famous methods for memorizing very long series of numbers. The basic idea is to associate a person, an action, and an object with each number from 00-100 to help encode big chunks of numbers; for example, number 73 could be Lisa (person), Celebrating (action), Birthday (object). The number 84 could be Peter (person), Playing (action), Piano (object) and 98 could be Beethoven (person), Drinking (action), Coffee (object). We can then apply the system when confronted with a number we need to memorize by chunking the long digits in units of two or three and then storing them in our Memory Palace. Because in English our syntax leads us to express simple sentences in person - action - object order, we retain the number using the P.A.O. system. For example, to memorize the number 738498:

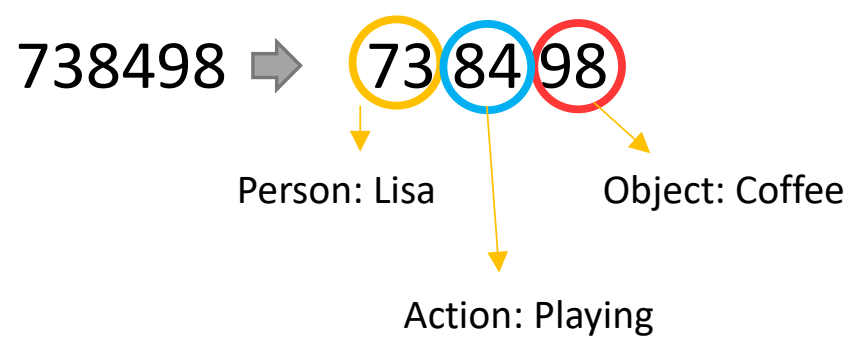

In this example we have "Lisa is playing coffee." One can add simple connecting words if it makes the image stronger, such as "Lisa is playing in coffee" or "Lisa plays with coffee." At the same time, we actively picture this P.A.O. in our imagination, then commit them to our Memory Palace. Most memory experts use similar methods to memorize large numbers of random digits or huge numbers of playing 
cards. The practical applications extend to their daily lives in such ways as

memorizing their passport numbers, family members' phone numbers, items for today's shopping list, or even medical terms.

\section{Create our own image}

The methods discussed above commonly use chunking digits and creating something memorable from images while visualizing the connection created by the imagination to help the brain to memorize complicated things with less effort. When we try to simply stick a message in our memory with no system, instead of understanding the message thoroughly and finding ways to store it in our brain using such tools as the Memory Palace, the Dominic System, or the PAO system discussed above, more than likely those messages will be forgotten easily. As you read here, you might still be able to recall those random items with illustrations that I gave in earlier pages. For example, do you still remember which item from the list was on fire? 


\title{
Memorizing is happiness
}

When we need memorize something in our daily life, including music, it can be a painful job. But according to Roger Chaffin's Expert Memory, ${ }^{39}$ he gave volunteers two different series of letters from the alphabet and asked them to read each line over once, then look away and repeat the series in order.

\author{
O “HEQFPMRDTBVAZGIKDLFWROXS" \\ O "YOUAREANEXPERTATREADING" \\ You probably recognize the second line as:
}

\section{"YOU ARE AN EXPERT AT READING." 40}

Obviously the second line is less difficult than the first line, because as soon as we discover a meaningful sentence buried in the second series, the letters chunk themselves into something larger than the sum of its components, and we can faultlessly recall the letters of the second line. "You have stored in your long-term (as opposed to working) memory somewhere between 50,000 and 100,000 words that you can immediately and automatically recognize, pronounce, and understand." 41

\footnotetext{
39 Chaffin, Roger, Gabriela Imreh, and Mary Crawford. "Expert Memory." Practicing Perfection: Memory and Piano Performance. Psychology, 2012

40 Chaffin et al., p. 67.

41 Ibid.
} 
He said that when we see a line we try to recognize the words as units, so called

"chunking." The same idea lies at the heart of the Dominic and PAO systems by chunking the digits or alphabet letters to form something meaningful.

This concept is of great benefit to us as pianists, for our retention and capacity to memorize increase effortlessly when we recognize the "chunks." When we see that a similar passage occurs in multiple places in the score, or the same octave leaps, or even seeing the same accompaniment in the left hand, that is our equivalent to those Memory Champion winners' ability to memorize a very long series of digits by chunking them to form meaningful messages. Therefore, when we try to recall them from memory, they are already there.

Many memory experts successfully memorize massive amounts of information. Some winners say that they were born with just average memory, not as so-called memory geniuses, but they continually self-trained to expand their memory skill. ${ }^{42}$ Moreover, the eight-time memory champion winner, Dominic O’Brien, was diagnosed with dyslexia. ${ }^{43}$ His teacher did not believe that he could achieve

\footnotetext{
42 Frishberg, Hannah. "How to Train Your Brain like a Memory Champion." New York Post. New York Post, 13 Nov. 2018. Web. https://nypost.com/2018/11/12/how-to-train-your-brain-like-a-memorychampion.

43 "Dominic O'Brien." Dyslexia Help at the University of Michigan. Web. http://dyslexiahelp.umich.edu/success-stories/dominicobrien\#: :text=\%E2\%80\%8BWhat\%20makes\%200'Brien's, uses\%20to\%20memorize\%20so\%20well.
} 
anything. However, $\mathrm{O}^{\prime}$ Brien's accomplishment and those achievements by great memory experts show that it is possible for our brain to do so much more than we believe. What is necessary is that we continually keep it active and train it.

Most music is far more complicated than random digits, letters, or a shopping list; it also involves multiple senses, including hearing, vision, and touch. According to Chaffin, "Piano performance involves motor (procedural) memory in a way that memorizing digits or chess boards does not. Motor memory develops automatically and, with practice, its functioning becomes largely unconscious." 44 This can mean that as pianists we take advantage of relying on repetition while practicing and developing motor memory.

If we ask, "How do you play from memory?" we might get an answer like this: "It just happens." Such an answer suggests that the pianist might depend mindlessly on motor memory, revealing important habits about his or her learning and practicing process. If pianists risk embarrassment or worse on stage by performing only from motor memory, then why sidestep the possibility of higher security? As pianists, we recognize "chunks" that we are familiar with. The more chunks we recognize, the easier it is to absorb and retrieve the chunks. Chaffin also suggests,

\footnotetext{
${ }^{44}$ Chaffin, Imreh, and Crawford, p. 70.
} 
"Committing information to long-term memory is a different kind of challenge for experts and novice. Because novices must work with smaller chunks than experts, they have more to store. The task for experts is simpler. Because they work in larger chunks, there is less to be remembered. I do not mean to minimize the expert's accomplishment- we are, after all, talking about things like young Mozart's ability to recall the Miserere- but this is why memorization for experts is so often effortless." ${ }^{45}$

Pianists might not be aware that they study and memorize music as "chunks." However, as Chaffin observes, pianists study the overview of a piece, noticing, for example, whether it is a binary form, sonata-allegro form, or a series such as A, B, C, etc. This happens in ways that resemble the process by which memory winners recall random digits as "chunks."

Chaffin recounts how two men, William Chase and Anders Ericsson, worked with a college student, referred to as SF, over the course of 18 months as he developed his ability to memorize longer and longer sequences of digits. His growing ability to memorize was a function of his familiarity with running times and dates as a jogger. He used domain-specific knowledge to give meaning to the numerical chunks he memorized. Chaffin applies this concept to music when he writes: "The

${ }^{45}$ Chaffin et al., p. 68. 
formal structure of classical (and most other forms of) music, with its divisions and subdivisions into movements, sections, themes, and motives, provides a ready-made hierarchical organization of the sort that SF had to create for himself." ${ }^{46}$ Chaffin calls this sort of organization a hierarchical retrieval scheme that allows the performer to retrieve their chunks in the correct order. Secondly, we find ways to avoid taking a wrong turn when we have highly confusing passages, because our understanding of those materials allows us to identify locations in the formal structure that keep us on the right track. In Chaffin's interview of students who had to memorize two different sets of information (Bach's Italian Concerto and random digits in a series), he discovered that students displayed a similarity in using hierarchical organization to remember their chunks, as in the chart below. It helped them to retrieve their memory correctly from an organized system (See figure 5).

${ }^{46}$ Chaffin et al., p. 70. 

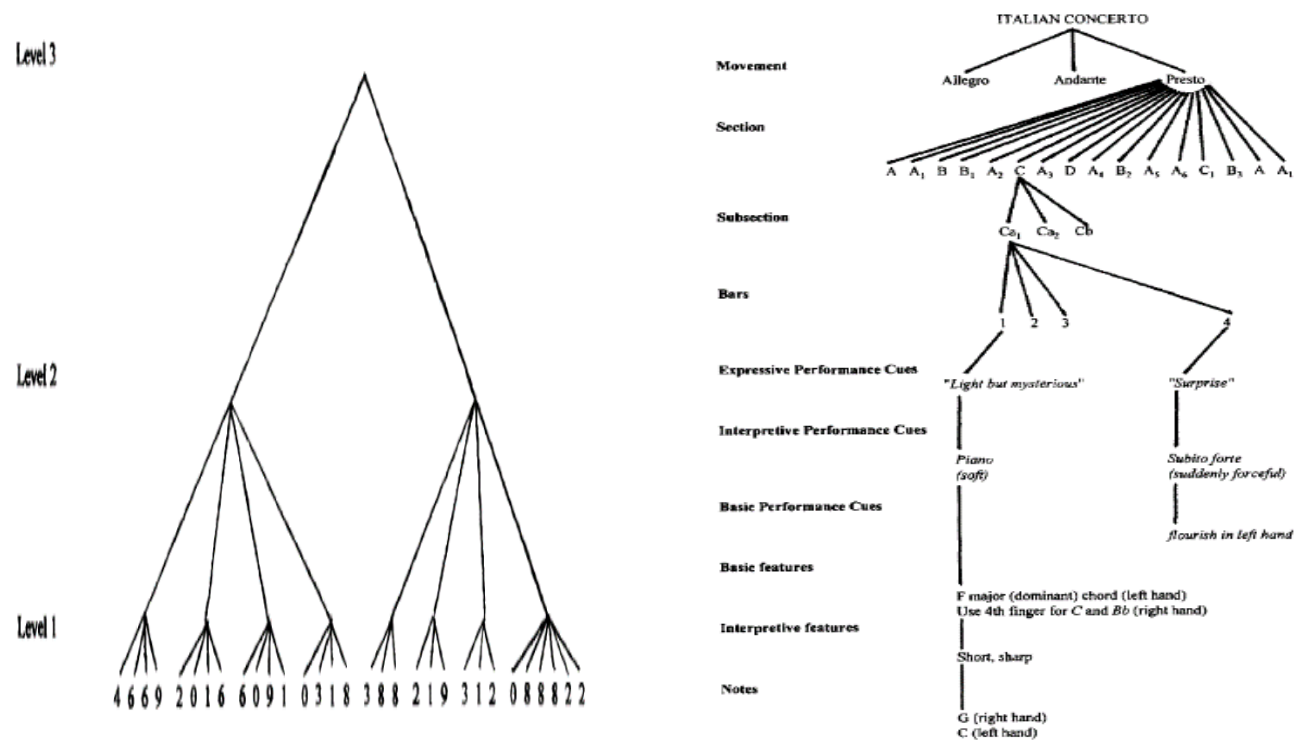

Figure 5: Left- The Retrieval Scheme used by SF for Recalling Strings of up to 30 Random Digits. ${ }^{47}$ Right- Hierarchical retrieval scheme for Bach's Italian Concerto ${ }^{48}$

However, after we have established the hierarchical organization of the piece, how do we study chunks? In order to retrieve our memory correctly and securely, we need to transfer the messages into meaningful information that we then input to our brain, as mentioned in the previous chapter. We begin a piece by studying the chunks thoroughly. This can come from the printed music, the sound, or the hand positions on the keyboard.

Studying thoroughly literally means phrase by phrase, bar by bar, or even beat by beat. Surely it involves a longer learning process than that employed by those
47 Ibid.
48 Chaffin et al., p. 200. 
pianists who can read music quickly and are able to play a challenging piece well within a single day. But it repays the extra effort in terms of security and a deeper understanding of the music; it also avoids too much reliance on motor memory during the learning process. It also pays back when we need to revisit pieces we have learned years ago and find that they have become easier and even stronger in memory.

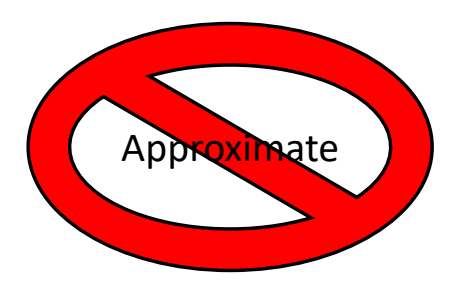

Approximate playing, approximate learning, approximate listening or approximate memorizing all encourage the possibility of something going wrong in performance. More importantly, they block us from the true freedom to enjoy the music we share on stage.

From my own experience, I once needed to resurrect two different concerti. I had initially learned each one with very different study processes: One I had put together quickly (my old "dangerous" habit). I could play it through fluently from the top to the end, yet it was not memorized at that point. The other concerto I had studied bar by bar and phrase by phrase; it also had taken much longer for me to learn the whole piece initially. However, by the time I finished learning this piece I 
had also memorized it. Unlike the former one, I had taken much more time to memorize it. Years later, however, on the day I needed to pick up both pieces for an event, I was shocked by how different the durability had been of each method. I had spent much more time in learning the latter piece, but it took drastically less time to pick up this piece again than it took me to relearn the one I could read through in its entirety in a much shorter period of time. The former piece required that I almost relearn it completely. I even doubted whether I had ever performed that piece before!

Different learning processes also impact our final performance onstage. I remember vividly that, while performing the former concerto which I had learned very quickly, I was extra nervous and deeply worried about having memory slips. Although the concert went well and no catastrophes occurred, the artistic level was less than it could have been. While performing, I could not completely enjoy the moment, because I was worried whether I could make it through "that part" or "that part" in those "gray areas" where I was not $100 \%$ sure of my memory.

However, with the other concerto, while I was also nervous in the green room before performing, I remember saying to myself, "I am ready. Let's share the music and enjoy it!" Strength does not just come from being confident; rather, confidence comes because each step of the learning process is solid. 
Studying thoroughly from the beginning means we develop an understanding of the structure (chunks), key signature, time signature, dynamic markingsessentially all the information in the printed music score. It is surprising how many pianists have a hard time telling you the key signature of the piece they are playing. Hands-separate practice is a method that effectively cleans up "gray areas." In my experience, most memory slips occur because of an insufficient understanding of the left-hand material; therefore, I focus even more on the left hand separately in practice. One of the ways that I often test myself, especially when the day of a performance is approaching, is to see if I can play through an entire piece slowly and hands separately, from memory. If I can do so, then I feel much more secure.

Often, when we play with both hands from memory, everything seems just fine. But when we play with one hand only, some potential uncertainties appear. Suggesting to our pupils to try practicing with one hand only is not to discourage them or embarrass them; instead, it is to help them locate the "gray areas" in their practice, where they are memorizing only approximately. The first few times, we might feel uncomfortable trying this ourselves, realizing that we suddenly do not know what to play next. This occurs, firstly, because we probably are not used to doing this and, secondly, because we do not know the music thoroughly enough to play safely from memory. Paradoxically, once we return the other hand to the keys so 
that both hands may play together, everything seems just fine again. This suggests

that we have been relying far too much on motor memory. Therefore, when we force ourselves to break down reliance on motor memory, we also reveal the potential problems. This appearance of a scary truth is not a bad thing at all, because now we know where we need to be clearer and stronger.

\section{Breaking rules}

Another way of forcing ourselves to challenge our motor memory is to play with two hands a part originally written for one hand. Among the benefits are that we oblige ourselves not to use motor memory, which can be frighteningly unreliable on stage, and that we can more easily explore voicing, which definitely encourages deeper listening.
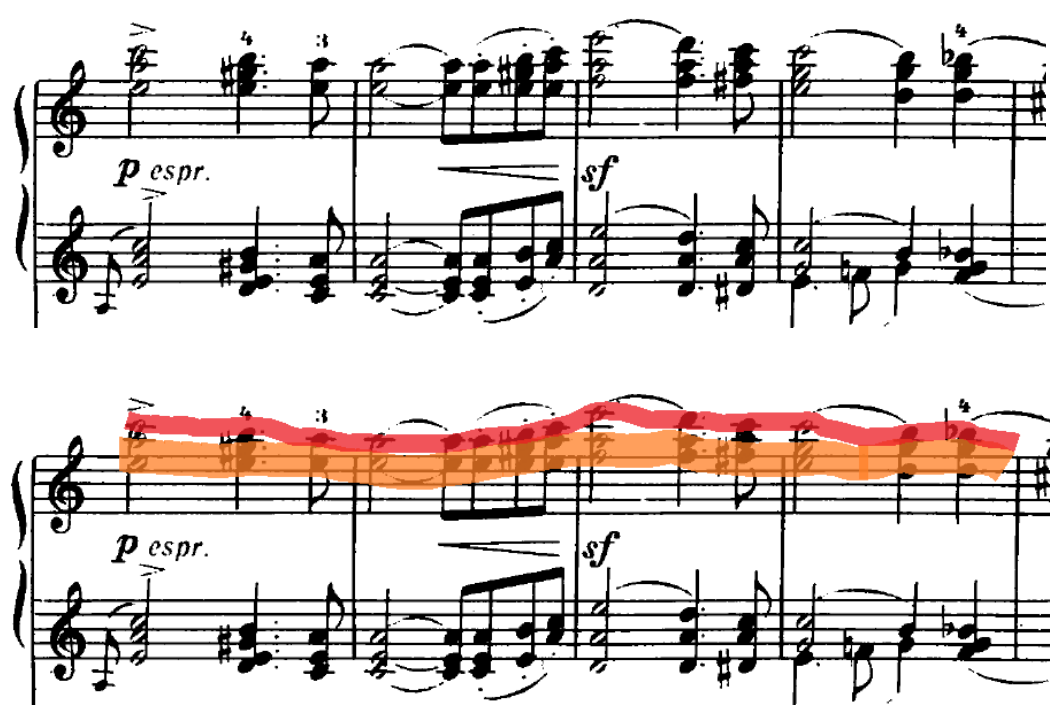

Figure 6: Schumann's Piano Concerto, 1st movement, mm. 12-15 Red line played by right hand, orange line played by left hand. 
Another useful practice tool that remarkably strengthens our knowledge of the music is the Stop-and-Play method, which requires us to "hear before we play," while also interrupting the motor memory. Before you play the next passage or measure, think thoroughly how you want it to sound and where you are going to start and stop, preferably knowing exactly which finger plays each note. Patiently waiting, taking time to think thoroughly at least once through the coming passage requires knowing clearly where you are going and what notes you are going to play. Only after this thinking process do you play. The first few attempts might not be satisfying or might even result in complete failure. Among the reasons might be that you did not think thoroughly enough or were too impatient to take enough time to visualize clearly what you are going to do next. If you do take enough time, but still fail, take a look at your music score. Congratulations! You have just discovered a "gray area."

\section{The shape of hand movement and directionality on keyboard}

You may have heard of the method called "Mapping," as introduced by Rebecca Payne Shockley in her book Mapping Music: for Faster Learning and Secure Memory. The idea is to use some unique diagram to map our piece in the early 
stages of the learning and memorizing processes. Ideally, the map becomes a

memory guide that we can follow instead of the printed music score (See figure 7).
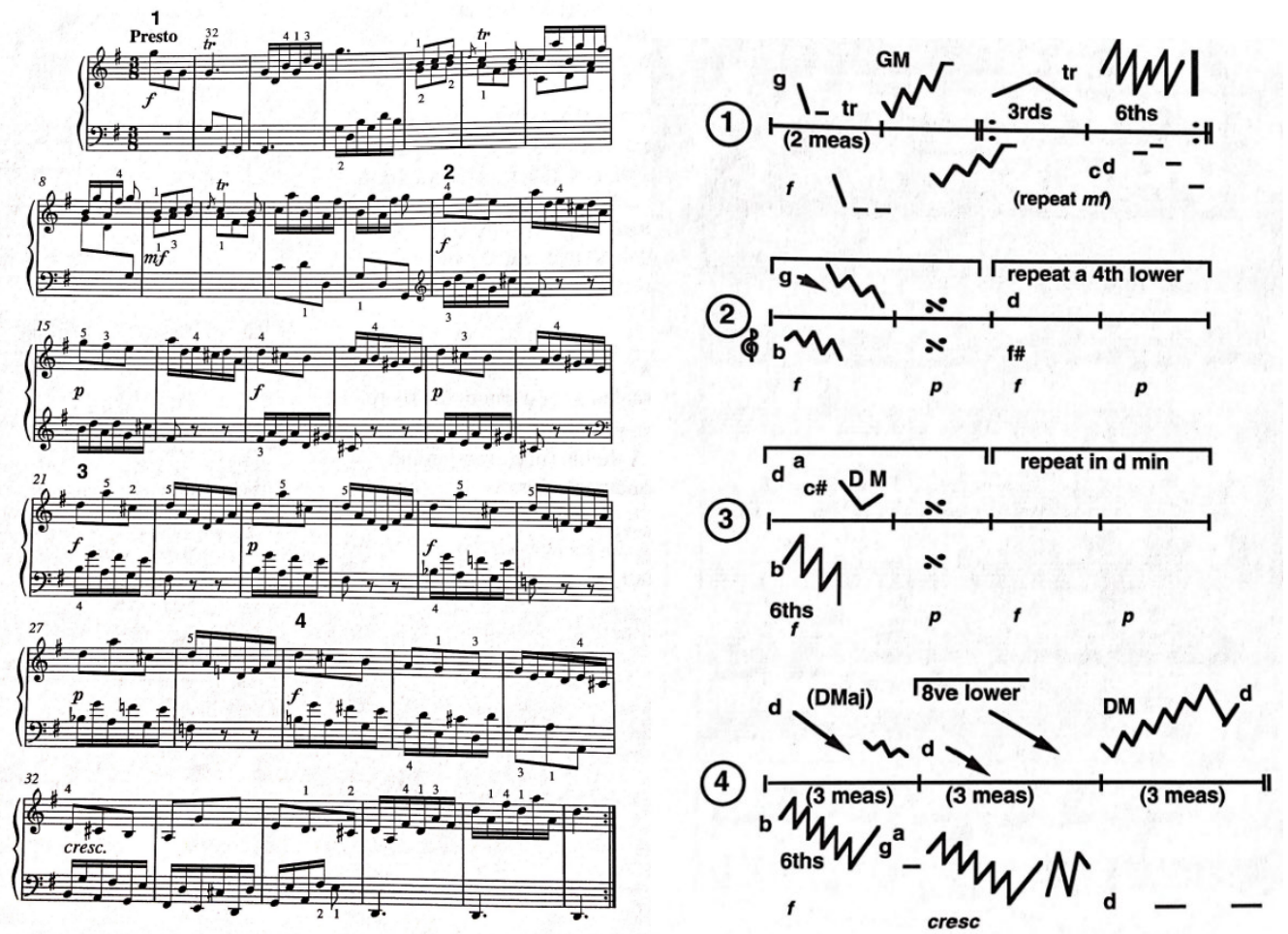

Figure 7: Mapping Music- Scarlatti: Sonata in G major, K. 2, L. $388^{49}$

I have tried this method with Beethoven's Piano Concerto No. 5, applying it to a very confusing passage where most pianists pray that nothing goes wrong. I used Schockley's method to make my diagram for that particular passage, along with

49 Shockley, Rebecca Payne. "Advanced Repertoire." Mapping Music: For Faster Learning and Secure Memory: A Guide for Piano Teachers and Students. A-R Editions, 2001. 64-65. 
"keywords" to remind me of what comes next. (A very similar idea called "retrieval cue" appears in the section "You got your answer" below.) I remember that what benefited my work the most with this method was actually the thinking process and the act of diagramming on paper: Is this melody going up or down? How about the left hand? Our brain is thinking when we are away from the piano (see figure 8). 

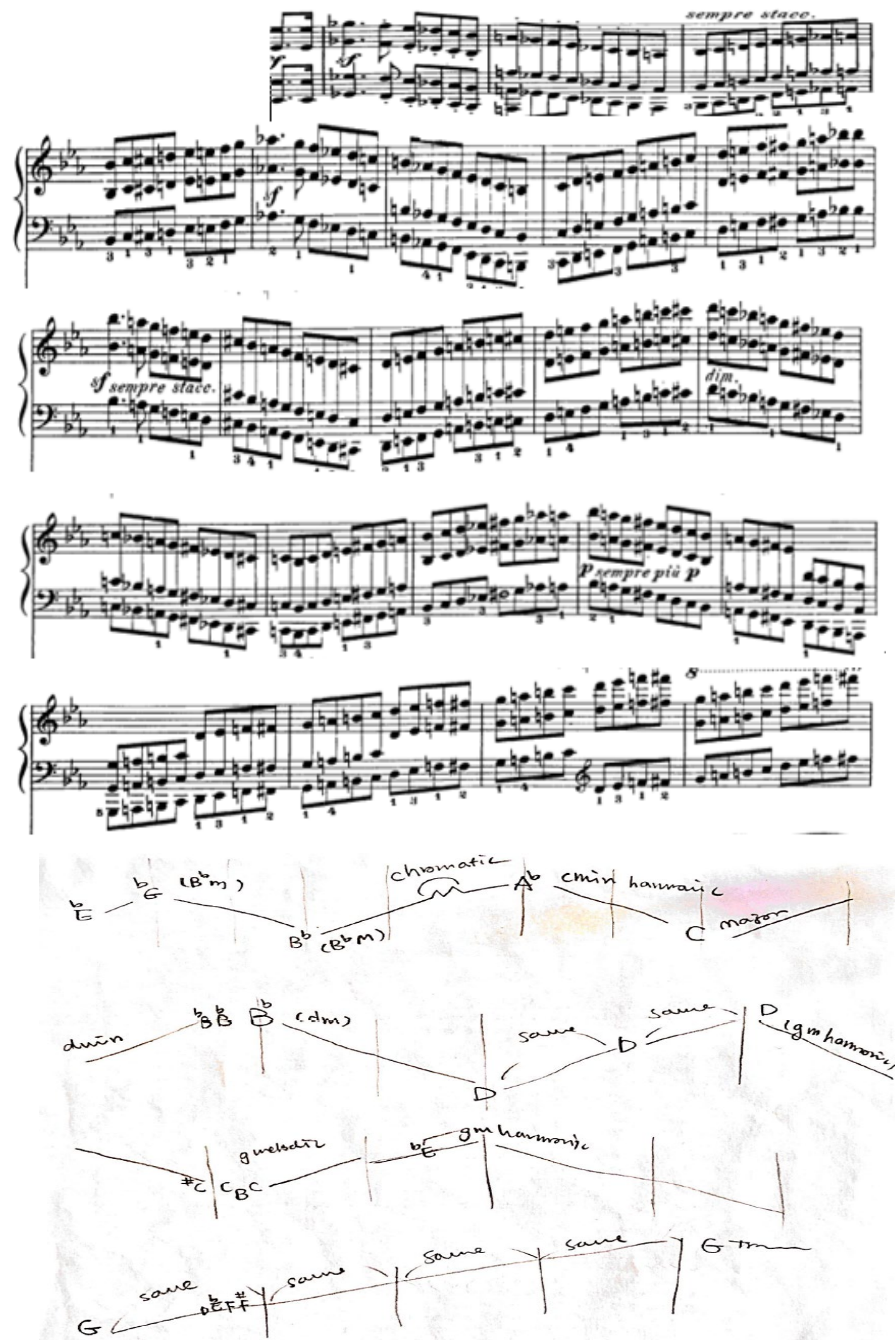

Figure 8: Beethoven's Piano Concerto, op. 73, 1st movement, mm. 307-329 
The thinking process involves an analysis that reveals our understanding of

the structure of music. Our own diagram serves as a reminder to give us a hint.

However, I found myself having a bit of disconnect between my diagram and actually playing on the keyboard. So I worked with an extension of the process in which, instead of diagramming the direction of melodic line, I mapped the direction on the keyboard (see figure 9). My personal map shows directional travel from black to white keys. It begins with the G-flat and continues along the descent. My map, however, is read from right to left, in accordance with travel down the keyboard. Horizontal arrows indicate movement from one key to another on the same physical plane. Points on a higher plane represent the elevated black keys, while points in the lower horizontal row represent the white keys. Diagonal arrows from point to point indicate movement from a black to a white key or a white key to a black key. This map is an example of how memorizing keyboard geography can be just as important as any other step in the memorization process.

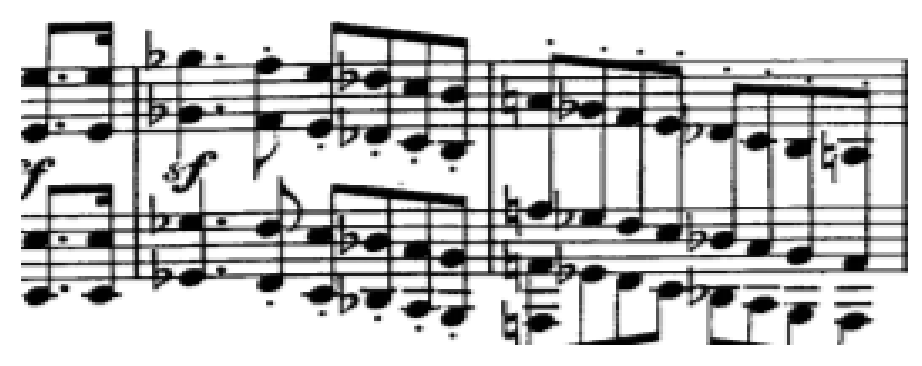




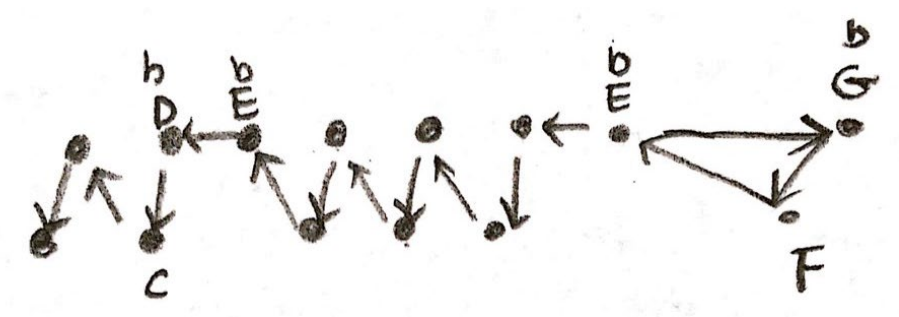

Figure 9: Beethoven's Piano Concerto, op. 73, 1st movement, mm. 307-309

I found that the extended mapping idea I revealed more of a connection

between my diagram and the actual playing on keyboard. Either Shockley's Mapping

Music idea or my small extended mapping idea can work well. Because the methods

involve a diagram, which we can perceive as a simplified version of the printed

music, the maps convey less information than the actual printed music score. While

simplifications can be useful, we must be extra careful about how often and how

long we should use this method, to avoid building up an "approximate-knowledge"

habit during our practice by reading only the diagram.

\section{All keys matter}

When I was a young student, I used to count how many C's or other notes

there were in a piece I was learning, or how many times I have to press the black

keys, although I didn't know at the time whether this really conveyed any benefits. At

least I enjoyed counting them! Since then, I still enjoy taking note of when the black

keys occur on the keyboard. It helps me clear up confusion in specific sections,

especially in passages with many accidentals that don't reveal clear patterns. If we 
see a passage as a whole, sometimes it might be difficult to memorize. But I found that highlighting only the black keys is surprisingly helpful for memorizing a passage. By only recognizing the black keys, we make it simpler in our brain, instead of thinking up and down, black and white, or white then black.

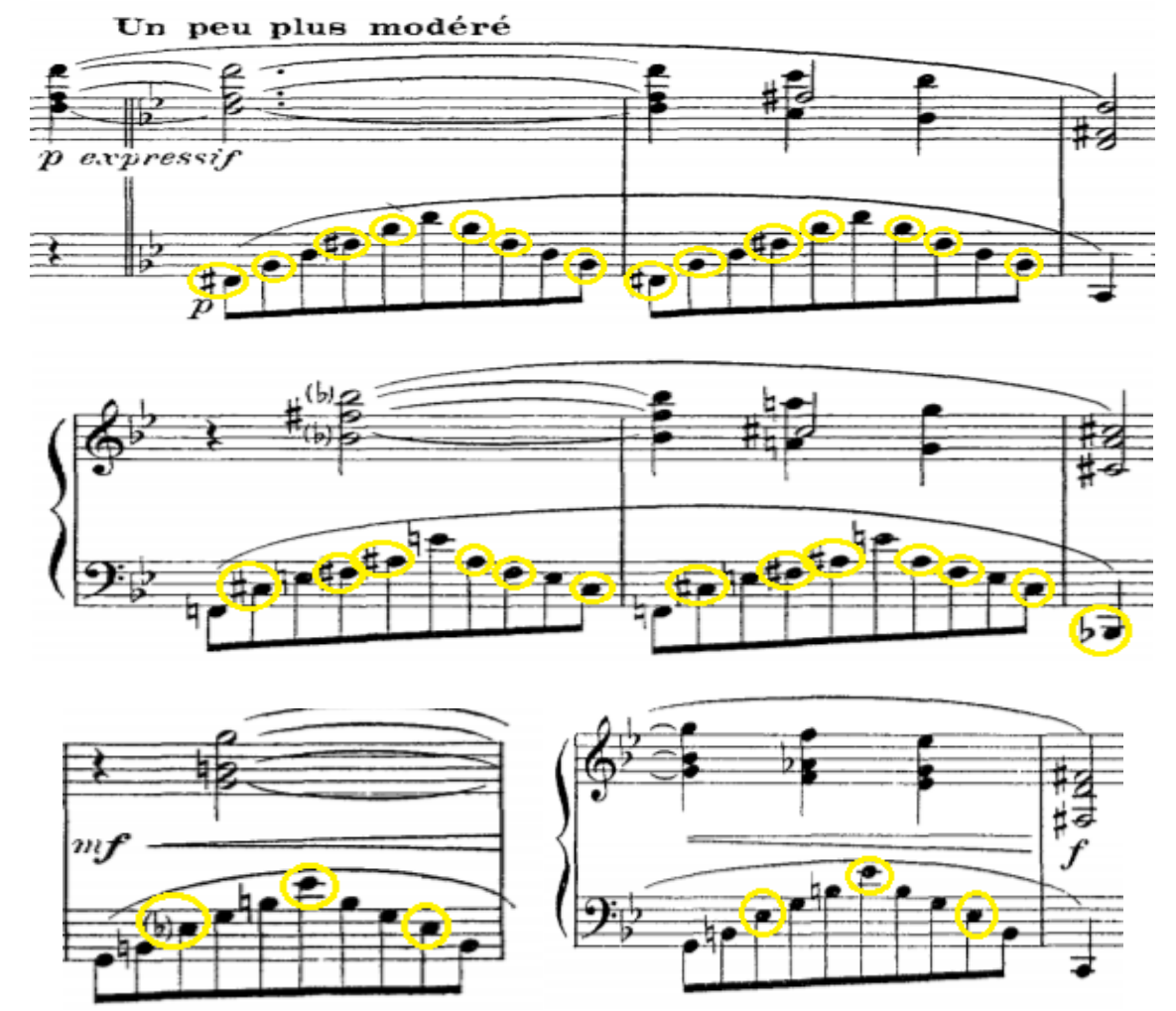

Figure 10: Ravel's La Valse, mm. 369-371, 374-375, 378-379

However, this strategy serves just to strengthen the memory, not to encourage us to take a shortcut. I personally use this "black key only" method when I have reached the phase that I have pretty much memorized the piece, yet I still want to strengthen the confusing passages that contain many accidentals. I have used this method for many years and have found it significantly helpful for memory security. 


\section{You got your answer}

"If you are going 80 miles per hour, how long will it take you to go 80 miles?" It seems too easy a question, but you might be surprised how many people fail to get the correct answer when they are in the hot seat. Most of us have also had the experience of looking for something which is sitting right in front of us, but we can't see it.

In Chapter 2, the given "keywords" on our designed diagram can serve as a reminder or hint to help keep us on track. In matters of performance, this idea is often referred to as "performance cues" or "retrieval cues." When memorizing a passage, we can look for a clue, a hint to help us feel more secure in performance (see figure 11).

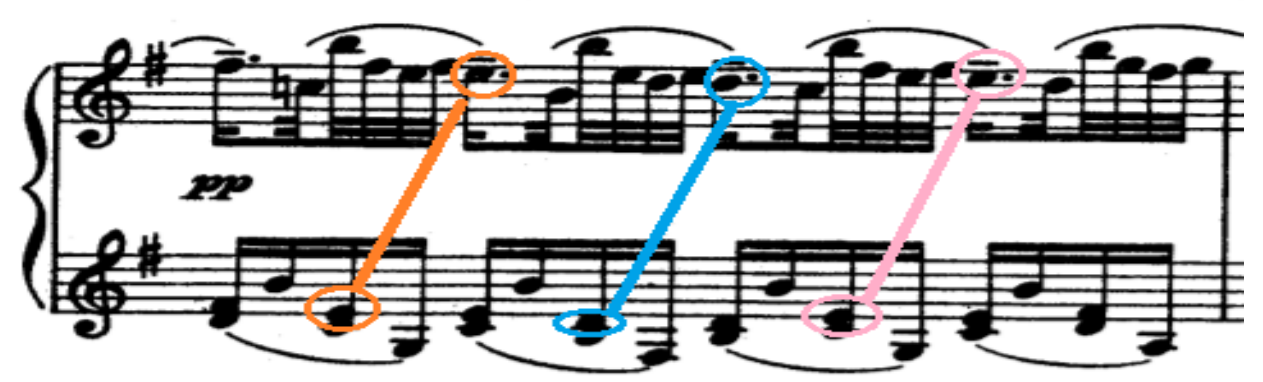

Figure 11: Rachmaninoff's Prelude, op. 32, no. 5, mm. 7-8 Left-hand inner voices can provide a hint for the right-hand arrival. 
Chaffin mentions that retrieval cues (so-called performance cues) can be built into our practice and serve as expressive, interpretive goals in the performance. " $\mathrm{A}$ performer must practice thinking about the 'artistic and inspirational elements' of a piece until the thought of these expressive goals for the piece becomes as automatic as the motor activity of the hands." 50 For example, "piano" dynamic becomes "mysterious," or "rapid passage" becomes "a bird flying through the mountains," etc. "The pianist practices while thinking of these expressive goals so that they come to mind during the performance to act as retrieval cues, eliciting the finely tuned motor responses."51 The idea behind this is that firstly we keep ourselves knowing which chunks we are playing. Secondly, by building "expressive goals" into our practice we prevent or eliminate the "potential worries" from taking over during our performance.

\section{Embracing forgetting.}

Most of us have things to memorize, whether in music, in study, or in our daily life. To that end, it is probably worthwhile to know how we actually forget things. From that angle, we will have a better chance for our information to last

\footnotetext{
50 Chaffin et al., p. 71.

51 Chaffin et al., p. 72.
} 
longer and also prevent forgetting. Hermann Ebbinghaus ${ }^{52}$ (1850-1909), a German psychologist who conducted some experiments on himself, showed how fast and how much our memory fades over time after we have learned specific information. The resulting graph is known as the "Ebbinghaus Forgetting Curve" (see figure 12). It is OK to forget! Forgetting is a part of the memorizing and learning process; it is natural. Some people might get frustrated that they keep forgetting over time. According to the "Ebbinghaus Forgetting Curve," 50 percent of newly learned information will be forgotten within 30 minutes. After the first day, approximately 70 percent will be gone. According to the Ebbinghaus's diagram, the speed of forgetting is not a constant rate. For example, you remember ten items, then the next day you forget two things, then the third day you forget two more things again.

52 https://www.encyclopedia.com/psychology/encyclopedias-almanacs-transcripts-andmaps/ebbinghaus-hermann-1850-1909. 


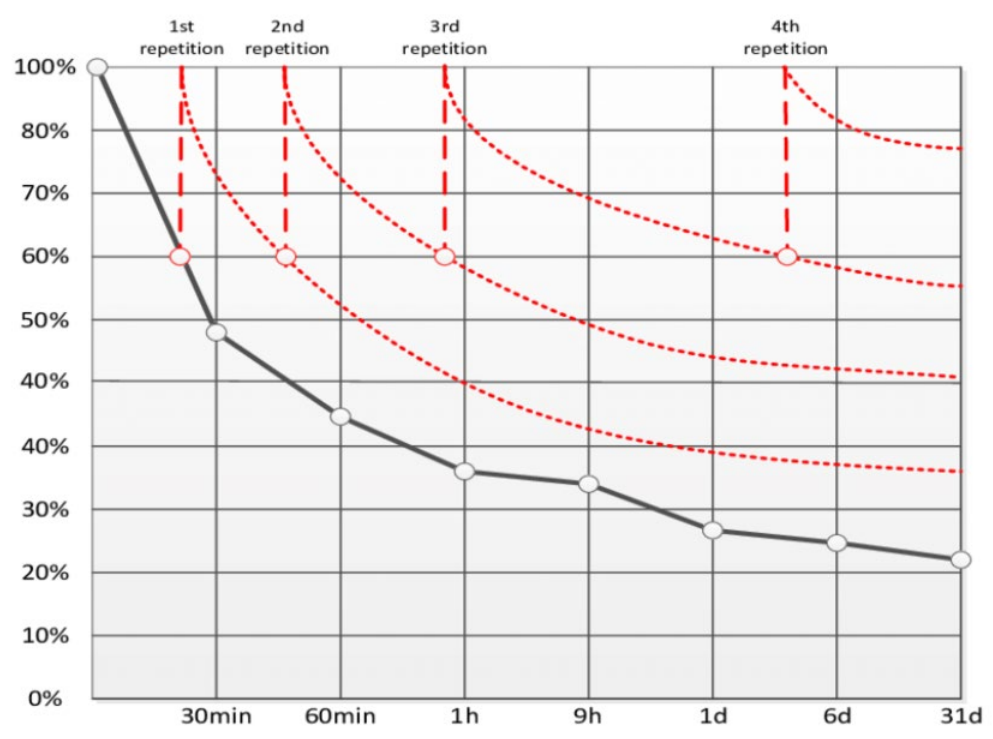

Figure 12: "Ebbinghaus Forgetting Curve" shows memory retention within 31 days..$^{53}$

Practice and review are extremely important regarding how long we

remember something we have learned. According to this diagram, after the first review of something previously learned, retention is longer than as seen in the first curve in black (without reviewing). With every time we review previously learned information, the forgetting curve flattens. Memory is retained longer and we forget less over time. According to Ebbinghaus's experiment, the flatter the forgetting curve, the more our learned information can stay in long-term memory. Therefore, regularly reviewing material indeed helps to convert information to long-term

53 https://www.researchgate.net/figure/Alteration-of-the-forgetting-curve-through-repetitionaccording-to-Ebbinghaus-1885-and_fig3_261952026 
storage. One method that helps us both to learn new materials and also to review

what we learned before is called "Spaced Repetition." ${ }^{4}$ This is a powerful method of reviewing, enabling us to keep our memorized information in long-term memory. The idea is that you review your material every other day. Meanwhile you keep adding new material, but you always review what you learned previously. Even spacing out review sessions within the same day also has potential to boost our memories.

Reviewing materials along with spacing materials out is more effective for building long term memory than cramming all the information in at once.

In "Spaced Repetition," the review cycle uses the numbers 1, 2, 6, 8, 15, and 26 to indicate precisely which days of the month (starting from the first day of learning) that you will work on a given new section. ${ }^{55}$ This means that a section will need a 26-day window of time to get a complete cycle of Spaced Repetition work. In a 31-day month, you can start new material for up to six days, which means you can divide a piece into as many as six working sections and finish within one month. For example, if I set a goal that I want to memorize a piece in a month, then I divide the piece into 5 sections and practice according to the schedule shown in Figure 13

\footnotetext{
54 Frank, Thomas. (2020, July 17). How to remember more of what you learn with spaced repetition. Retrieved from https://collegeinfogeek.com/spaced-repetition-memory-technique/ 55 Chen, Lily. "我都如何安排背單字計畫 長期記憶法傳授 (附計劃表) [How do I schedule my vocabulary in long-term memory.] Chen Lily." YouTube. YouTube, 05 Aug. 2019. Web. https://www.youtube.com/watch?v=zbu9WBAZCZE\&amp;ab_channel=ChenLily
} 
below. This idea also can be applied with the Fibonacci number series, which is 1,1 , $2,3,5,8,13 \ldots$ etc. The least recommended way to memorize is to wait until we have forgotten everything and then pick it up again, because that means our "Forgetting curve" will never advance beyond the first curve (presented in black on the "Ebbinghaus Forgetting Curve," as shown in Figure 12 above).

\begin{tabular}{|c|c|c|c|c|c|c|}
\hline Mon & Tues & Wed & Thurs & Fri & Sat & Sun \\
\hline $03 / 01$ & $03 / 02$ & $03 / 03$ & $03 / 04$ & $03 / 05$ & $03 / 06$ & $03 / 07$ \\
\hline \multirow[t]{2}{*}{$03 / 08$} & \multirow[t]{2}{*}{$03 / 09$} & $03 / 10$ & $03 / 11$ & $03 / 12$ & $03 / 13$ & $03 / 14$ \\
\hline & & 11 & 1122 & $2 \longdiv { 3 }$ & 344 & $4 \longdiv { 5 }$ \\
\hline $03 / 15$ & $03 / 16$ & $03 / 17$ & $03 / 18$ & $03 / 19$ & $03 / 20$ & $03 / 21$ \\
\hline 15 & 2 & 13 & 24 & 35 & 4 & 5 \\
\hline \multirow[t]{2}{*}{$03 / 22$} & $03 / 23$ & $03 / 24$ & $03 / 25$ & $03 / 26$ & $03 / 27$ & $03 / 28$ \\
\hline & & 1 & 2 & 3 & 4 & 5 \\
\hline \multirow[t]{2}{*}{$03 / 29$} & $03 / 30$ & $03 / 31$ & \multirow[t]{2}{*}{$04 / 01$} & \multirow[t]{2}{*}{$04 / 02$} & \multirow[t]{2}{*}{$04 / 03$} & $04 / 04$ \\
\hline & & & & & & 1 \\
\hline $04 / 05$ & $04 / 06$ & $04 / 07$ & $04 / 08$ & \multirow[t]{2}{*}{$04 / 09$} & \multirow[t]{2}{*}{$04 / 10$} & \multirow[t]{2}{*}{$04 / 11$} \\
\hline 2 & 3 & 4 & 5 & & & \\
\hline
\end{tabular}

Figure 13: Schedule of Spaced Repetition work in a 31-day month ${ }^{56}$

56 "Memory Stack: Best Plan to Memorize Vocabulary: https://milletbard.com/26Memory/\#/ 


\section{Chapter 3}

\section{For whom are you performing?}

Maybe we're playing for someone special in our life, for an individual person sitting in the concert hall, just for ourselves, or even none of the above. Whether we choose a particular person to perform for or not, we should perform our precious music from the depths of our heart.

After students gain a basic understanding of a piece, sometimes we hear questions: "Do you think I should play louder here?" "Do you think I should slow down there?" I must admit that I raised such questions frequently with my teachers during my high school and undergraduate studies in Taiwan. The teaching-learning cycle there and many other places trains us to seek a "correct answer" which matches our teacher's taste. Literally, every note counts in the process of fulfilling our teacher's "expectation."

The first thing I would see my teacher do at the start of my piano lesson was to pull out their set of 120 colored pencils and choose one color which had not been used in my past lessons. After what sometimes resembled an art lesson, my music score often looked more and more like a rainbow. Eventually my score would be completely filled with many different colors and I would purchase a new one. During that period of time, it was normal for me to have owned at least three copies of my 
pieces, not because I lost my scores, but because there was no more empty space to

fill in more color. So I kept purchasing new "canvases" for my teacher to paint her art.
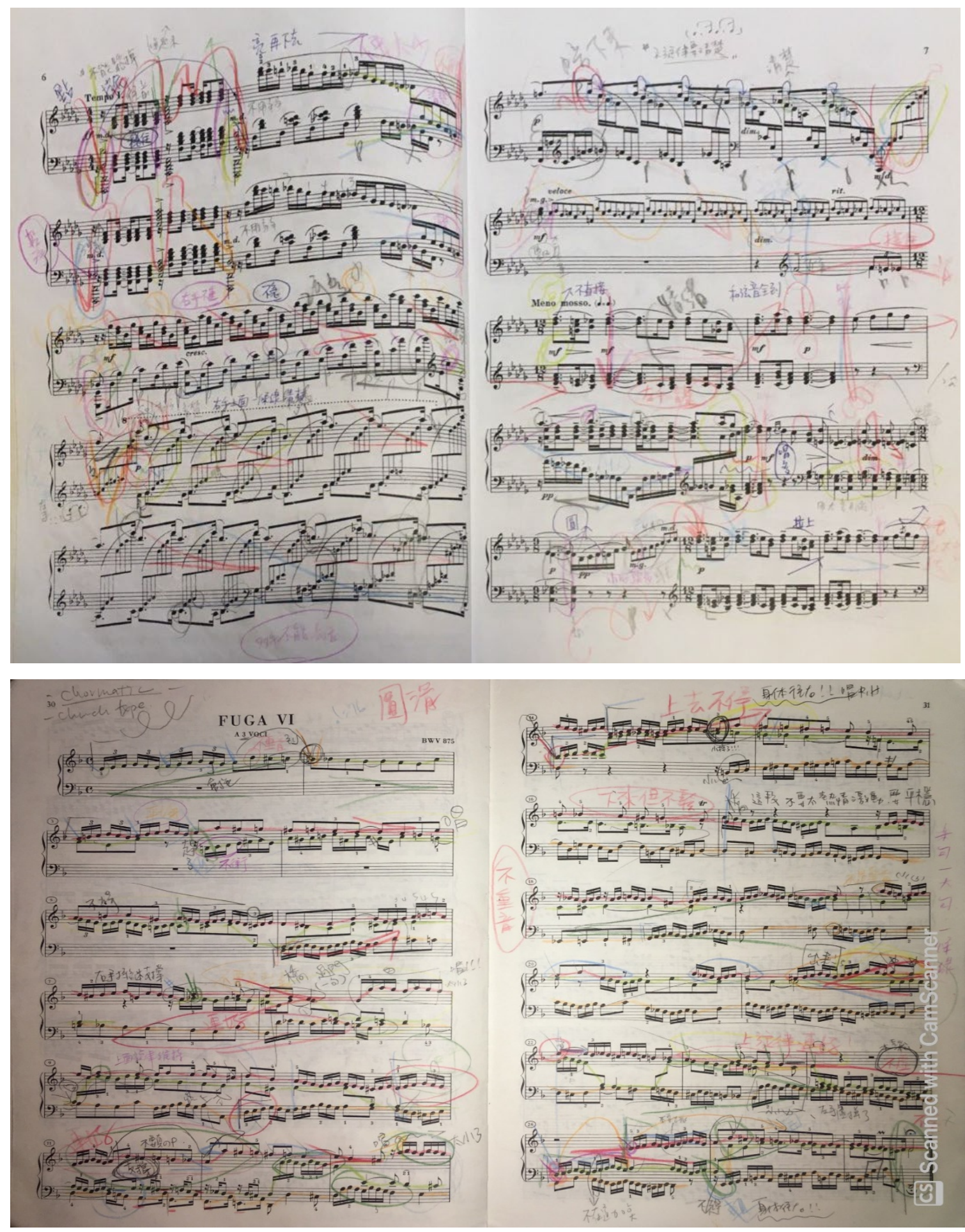

Figure 14: Rachmaninoff's Piano Sonata, no. 2, op. 36, and Bach WTC // BWV 875, my personal copies 
I studied with at least ten teachers during my piano journey in Taiwan. It is

probably not a coincidence that they all displayed a similar style of not asking certain questions of the student: "What do you think?" "What do you hear?" Instead, they shared their views: "I think this." "And I hear that."

As soon as they had expressed their views, right away my music score gained another color, another warning sign: "You must do this!" Despite hours and hours in the practice room and finally presenting our hard work on stage, in the end it was not "our" music, but the "teacher's" music. Thoughts that went through my mind on stage included: "This phrase must be louder." "My teacher told me to slow down here." "Oh, I hope she/he didn't hear that!"

The fear and worries about making "correct" music for someone else to judge impacted me directly, creating tension, both mentally and physically. Such fears never go away, neither in recitals and competitions, nor afterward. Once implanted, they remain. And the physical tension also led to injury.

Thankfully, that's all in the past now. The teachers I have studied with here in the United States have consistently created an environment in which I seek to do my best, but without feeling stressed or afraid. Totally gone are the very real worries about crying or being physically hit during a lesson. When teacher and student can 
even laugh together, I feel that I can express anything from my heart in my music without being judged.

Now a piano lesson feels more like sharing and discussing ideas together, instead of being commanded what to do about each note and each measure, following someone else's vision of the music. Now I know that I can trust the music that I hear within. And I want my future students to learn to trust their own music in the same life-affirming way.

It's one big circle of teaching and learning. If the teacher-student relationship builds in a healthy way, the student will be well enough informed to trust themselves, not through a path of obedience (or its chaotic opposite, total freedom), but rather through a process of intelligent and inspired discovery.

"Whoever is moved by music to the depths of his soul, and works on his instrument like one possessed, who loves music and his instrument with passion, will acquire virtuoso technique; he will be able to recreate the artistic image of the composition; he will be a performer." ${ }^{57}$

57 Neuhaus, Heinrich. The Art of Piano Playing. Translated by K.A. Leibovitch. Kahn \& Averill, 1993, 29. 


\section{Conclusion}

The two most powerful things in the world.

On stage, at that amazing moment just before we press the very first note on the keyboard, we have already given our practice time to the music and now we are sharing the music all together in the same room. I often see the performer as a bridge, a connection between music and the listeners. We convey our messages and our stories through the music.

Neuhaus reminds us of "Pasternak's wonderful words: 'Hearing is an organ of the soul.'" 58 We play the way we sing, we play how we feel, and we play how we love. "Our own life has to be our message." ${ }^{59}$ It is the same for the music we perform.

When we participate as listeners in the concert hall, we often give our full support and love to whomever is sitting on the stage and ready to share their music. However, when it is our turn to be onstage, some of us might start to worry: "They are looking at me now. I can't make mistakes, because they will know."

Why do we feel so different because we happen to be sitting in a different seat in the same hall? If there is even one person who hopes to see us fail on stage,

\footnotetext{
58 Neuhaus, p. 27.

59 "A Quote from The World We Have." Goodreads. Goodreads. Web. https://www.goodreads.com/quotes/39624-our-own-life-has-to-be-our-message
} 
then that person does not deserve even a bit of our concern, nor even to listen to our performance!

There is an old saying that the two most powerful forces in the universe are Love and Fear. Which we choose in performance will certainly affect the result. In any occasion, once we base our decisions on Love, rather than Fear, our outlook changes instantly, with direct impact on the physical body and the mind.

We can choose to love our music and embrace the fear. "The more we practice, the more we are gentle with our fear and are able to embrace it, the more the fear goes away." 60 


\section{BIBLIOGRAPHY}

Bernstein, Seymour. With Your Own Two Hands: Self-Discovery through Music. Schirmer Books; Collier Macmillan, 1981.

Brower, Harriette Moore. The Art of the Pianist: Technic and Poetry in Piano Playing, for Teacher and Student. New York, NY: C. Fischer, 1911.

Brown, William. Menahem Pressler: Artistry in Piano Teaching. Bloomington and Indianapolis, IN: Indiana University Press, 2009.

Cooke, James Francis. How to Memorize Music. Ann Arbor, MI: University Microfilms International, 1979.

D'Abreu, Gerald. Playing the Piano with Confidence: an Analysis of Technique, Interpretation, Memory and Performance. New York: St Martin's Press, 1965.

Foldes, Andor. Keys to the Keyboard: a Book for Pianists. London: Oxford University Press, 1950.

Gát József, and Kleszky István. The Technique of Piano Playing. London: Collets, 1974.

Gieseking, Walter and Karl Leimer. Piano Technique, Dover Publ. 1972

Hanh, Thich Nhat. Fear: Essential Wisdom for Getting through the Storm. New York: HarperOne, 2014.

Hanh, Thich Nhat. No Mud, No Lotus: The Art of Transforming Suffering. Parallax, 2014.

Hughes, Edwin. "Musical Memory in Piano Playing and Piano Study." The Musical Quarterly, vol. 1, no. 4, 1915

Klickstein, Gerald. The Musician's Way: A Guide to Practice, Performance, and Wellness, Oxford University Press, USA, 2009 
Kochevitsky, George A. The Art of Piano Playing: a Scientific Approach. Evanston, IL: Summy-Birchard Co., 1967.

Lhevinne, Josef. Basic Principles in Piano Playing. Musical Scope Publishers. New York, New York, 1971

Lowe, C. Egerton. The Art of Pianoforte Practising: with an Appendix on LegatoPedalling. London: Novello, 1928.

Mackinnon, Lilias. Music by Heart. Westport, CT: Greenwood Pr., 1981.

Matthay, Tobias. Musical Interpretation: Its Laws and Principles, and Their Application in Teaching and... Performing (Classic Reprint). Books for Libraries Press., 2015.

Neuhaus, Heinrich. The Art of Piano Playing, trans. K.A. Leibovitch. London: Kahn \& Averill, 1993.

Pierce, Alexandra. Deepening Musical Performance through Movement: the Theory and Practice of Embodied Interpretation. Bloomington, IN: Indiana University Press, 2010.

Shinn, Frederick G. Musical Memory and Its Cultivation. Augener Ltd. London., 2017.

Shockley, Rebecca Payne. Mapping Music: for Faster Learning and Secure Memory: a Guide for Piano Teachers and Students. Middleton, WI: A-R Editions, 2001.

Williamon, Aaron. The Value of Performing from Memory, Psychology of Music, 1999 
Online resources:

"A Quote from The World We Have." Goodreads. Goodreads. Web. 03 Apr. 2021. https://www.goodreads.com/quotes/39624-our-own-life-has-to-be-our-message

Alred Reisenauer: https://www.forte-piano-pianissimo.com/Alfred-Reisenauer.html

Bernardi, Nicolò Francesco, Alexander Schories, Hans-Christian Jabusch, Barbara Colombo, and Eckart Altenmüller. "Mental Practice in Music Memorization: An Ecological-Empirical Study." University of California Press. University of California Press, 01 Feb. 2013. Web. 03 Apr. 2021. https://online.ucpress.edu/mp/articleabstract/30/3/275/62568/Mental-Practice-in-Music-Memorization-

An?redirectedFrom=fulltext.

"Do Goldfish Really Have a Memory of 3 Seconds." Social Beat. 28 Jan. 2021. Web. 05 Apr. 2021.

https://socialbeat.in/youtube-seo-tips/wp-content/uploads/u99srn6/b5fcc0-dogoldfish-really-have-a-memory-of-3-seconds

Dominic O'Brien: https://peakperformancetraining.org/

Dominic O'Brien In an interview with CNNMoney Switzerland's Amanda Kayne: https://www.youtube.com/watch?v=ACw5YVgg4lc\&ab channel=ArchiveTV

"Dominic O'Brien." Dyslexia Help at the University of Michigan. Web. 02 Apr. 2021. http://dyslexiahelp.umich.edu/success-stories/dominicobrien\#: :text=\%E2\%80\%8BWhat\%20makes\%200'Brien's, uses\%20to\%20memorize\% 20so\%20well.

"Ebbinghaus, Hermann." Encyclopedia.com. Encyclopedia.com, 05 Apr. 2021. Web. 05 Apr. 2021.

https://www.encyclopedia.com/psychology/encyclopedias-almanacs-transcripts-andmaps/ebbinghaus-hermann-1850-1909.

Fundamentals of Piano Practice http://pianofundamentals.com/book/en/chapter 1 
Frank, Thomas (2020, July 17). How to remember more of what you learn with spaced repetition. Retrieved from https://collegeinfogeek.com/spaced-repetitionmemory-technique/

Frishberg, Hannah. "How to Train Your Brain like a Memory Champion." New York Post. New York Post, 13 Nov. 2018. Web. 02 Apr. 2021.

https://nypost.com/2018/11/12/how-to-train-your-brain-like-a-memory-champion.

Handwerk, Brian. Neuroscientists Unlock the Secrets of Memory Champions. 13 Mar. 2017, www.smithsonianmag.com/science-nature/why-you-can-train-your-brainmemory-champion-still-forget-your-car-keys-180962496/.

Harvard Health. "Preserving and Improving Memory as We Age." Harvard Health. Web. 26 Nov. 2020.

https://www.health.harvard.edu/newsletter article/preserving-and-improvingmemory-as-we-age

Hoffeld, David. "Your Brain Can Do More Than You Think It Can, Says Science." Fast Company. Fast Company, 17 Feb. 2017. Web. 26 Nov. 2020.

https://www.fastcompany.com/3065915/your-brain-can-do-more-than-you-think-it$\underline{\text { can-says-science }}$

Kristensson, Sophia. "World Champion Teaches You How to Remember." Chalmers. 05 Oct. 2018. Web. 01 Apr. 2021.

https://www.chalmers.se/en/news/Pages/world-champion-teaches-you-how-toremember.aspx

Lang Lang: https://www.langlangofficial.com/

“Mooji - Mooji." Mooji.org. Web. 16 Nov. 2020. https://mooji.org/mooji

Moore, J. Kenneth. "The Pipa." In Heilbrunn Timeline of Art History. New York: The Metropolitan Museum of Art, 2000-.

http://www.metmuseum.org/toah/hd/pipa/hd pipa.htm

Piano Street. http://pianostreet.com 
"Set the Deadline to Achieve Your Goals." 10 Aug. 2018. Web. 29 Mar. 2021. https://weidelonwinning.com/blog/set-the-deadline-to-achieve-your-goals/

"The Power of Asking Yourself Questions." The Emotion Machine, 9 Dec. 2018, www.theemotionmachine.com/the-power-of-asking-yourself-questions/

Thich Nhat Hanh: https://plumvillage.org/about/thich-nhat-hanh/

Viennese Masters Orchestra Invitational. 30 Mar. 2021. Web. 31 Mar. 2021. https://viennesemasters.org/about/

Watts, Alan. "Quotes." Alan Watts Organization. 21 Mar. 2021. Web. 31 Mar. 2021. https://alanwatts.org/quotes/

Wolff, David Michael. "Practicing." The Carolina Philharmonic. The Carolina Philharmonic, 14 Dec. 2015. Web. 18 Nov. 2020. https://www.carolinaphil.org/zenand-the-art-of-piano/practicing

What to learn next? Content selection support in mobile game-based learning Scientific Figure on ResearchGate. Available from:

https://www.researchgate.net/figure/Alteration-of-the-forgetting-curve-throughrepetition-according-to-Ebbinghaus-1885-and fig3 261952026

"30+1 Ways To Help You Memorize Music Flawlessly." 30+1 Ways To Help You Memorize Music Flawlessly. Web. 03 Apr. 2021.

https://collaborativepiano.blogspot.com/2007/07/memorization-tips-and-hacks.html

“郎朗教小朋友上钢琴课太搞笑了太有激情了” YouTube. YouTube, 17 Nov. 2019.

Web. https://www.youtube.com/watch?v=WJlivg4x7rg

Chen, Lily. "我都如何安排背單字計畫 長期記憶法傳授（附計劃表）// Chen Lily." YouTube. YouTube, 05 Aug. 2019. Web.

https://www.youtube.com/watch?v=zbu9WBAZCZE\&amp;ab channel=ChenLily

"MemoryStack: Best Plan to Memorize Vocabulary: 背單字計畫產生器." Web. https://milletbard.com/26Memory/\#/ 